\title{
Fitossociologia e análise temporal do fragmento florestal urbano Capoeira do Black,
} Belém, Pará

\author{
Phytosociology and temporal analysis of the urban forest fragment Capoeira do Black, Belém, Pará \\ Fitosociología y análisis temporal del fragmento de bosque urbano Capoeira do Black, Belém, Pará
}

Recebido: 24/01/2021 | Revisado: 24/01/2021 | Aceito: 30/01/2021 | Publicado: 07/02/2021

\author{
Caio Felipe Almeida Rodrigues \\ ORCID: https://orcid.org/0000-0002-8676-1665 \\ Universidade Estadual do Pará, Brasil \\ E-mail: caiorodrigues.eng@gmail.com \\ Ademir Roberto Ruschel \\ ORCID: https://orcid.org/0000-0002-0352-5238 \\ Embrapa Amazônia Oriental, Brasil \\ E-mail: ademir.ruschel@embrapa.br \\ Fernanda da Silva Mendes \\ ORCID: https://orcid.org/0000-0003-0580-4473 \\ Universidade Estadual do Pará, Brasil \\ E-mail: mendes.fsm@gmail.com \\ Francimary da Silva Carneiro \\ ORCID: https://orcid.org/0000-0002-1693-8779 \\ Universidade Federal Rural da Amazônia, Brasil \\ E-mail: francimarycarneiro@gmail.com \\ Jéssica Costa dos Santos \\ ORCID: https://orcid.org/0000-0002-4424-1821 \\ Escola Superior de Agricultura Luiz de Queiroz, Brasil \\ E-mail:jessicasantos.ufra@gmail.com \\ Madson Alan Rocha de Sousa \\ ORCID: https://orcid.org/0000-0002-7560-3274 \\ Universidade Estadual do Pará, Brasil \\ E-mail:madsonalan@uepa.br
}

\begin{abstract}
Resumo
Objetivando caracterizar a composição florística, diversidade, estrutura horizontal, estágio sucessional e a dinâmica de ocupação do solo do fragmento florestal de uma área de floresta secundária localizada na zona periurbana do município de Belém, Pará. Foi realizado um Censo Florestal mensurando todos os indivíduos com diâmetro maior ou igual a $15 \mathrm{~cm}$ e um Inventário amostral de oito parcelas permanentes. As espécies foram classificadas em grupos ecológicos. Quanto à composição e à riqueza, foi feita uma listagem de espécies e calculada a representatividade amostral por entre as diferentes unidades amostrais. A dinâmica de ocupação do solo foi realizada no método Isodata. No Censo foram mensurados 2.163 indivíduos, 171 espécies e 51 famílias botânicas e na amostragem por parcelas foram encontrados 2.309 indivíduos, 186 espécies e 52 famílias. O índice de diversidade de Shannon foi de $H^{\prime}=4,35$ nats.ind a uma equabilidade de $\mathrm{J}^{\prime}=0,83$, apontando uma alta diversidade florística na área. O grupo de espécies de maior predominância foi o das secundárias tardias e na análise multitemporal da cobertura do solo foi possível verificar 95,8\% é floresta secundária em estágio médio de regeneração. Os parâmetros dendrométricos de densidade e área basal tiveram valores aproximados aos encontrados em remanescentes de florestas primárias e secundárias da região amazônica; o ambiente de borda apresentou parâmetros florísticos-estruturais um pouco superior em relação ao ambiente do interior, com exceção do parâmetro área basal que foi maior no interior do fragmento e por meio da análise do estágio sucessional e dinâmica da cobertura do solo.
\end{abstract}

Palavras-chave: Florestas urbanas; Sucessão secundária; Cobertura do solo.

\begin{abstract}
Aiming to characterize the floristic composition, diversity, horizontal structure, successional stage and the dynamics of land occupation of the forest fragment of a secondary forest area located in the periurban area of the municipality of Belém, Pará. A Forest Census was carried out measuring all individuals with diameter greater than or equal to 15 $\mathrm{cm}$ and a sample inventory of eight permanent plots. The species were classified into ecological groups. As for composition and richness, a species listing was made and the sample representativeness was calculated among the different sample units. The dynamics of land occupation was performed using the Isodata method. In the Census, 2,163 individuals, 171 species and 51 botanical families were measured and in the sampling by plots, 2,309 individuals, 186 species and 52 families were found. Shannon's diversity index was $H^{\prime}$ '= 4.35 nats.ind to an equability
\end{abstract}


of $\mathrm{J}^{\prime}=0.83$, indicating a high floristic diversity in the area. The group of species with the most predominance was the late secondary species and in the multitemporal analysis of the soil cover it was possible to verify $95.8 \%$ is secondary forest in medium stage of regeneration. The dendrometric parameters of density and basal area had values close to those found in remnants of primary and secondary forests in the Amazon region; the edge environment presented floristic-structural parameters a little higher than the interior environment, with the exception of the basal area parameter which was greater inside the fragment and through the analysis of the successional and dynamic stage of the soil cover.

Keyword: Urban forests; Secondary succession; Land cover.

\section{Resumen}

Con el objetivo de caracterizar la composición florística, diversidad, estructura horizontal, etapa sucesional y la dinámica de ocupación de la tierra del fragmento de bosque de un área de bosque secundario ubicado en el área periurbana del municipio de Belém, Pará. Se realizó un Censo Forestal midiendo todos los individuos con diámetro mayor o igual a $15 \mathrm{~cm}$ y un inventario de muestra de ocho parcelas permanentes. Las especies se clasificaron en grupos ecológicos. En cuanto a composición y riqueza, se realizó un listado de especies y se calculó la representatividad muestral entre las diferentes unidades muestrales. La dinámica de ocupación del suelo se realizó mediante el método Isodata. En el Censo se midieron 2.163 individuos, 171 especies y 51 familias botánicas y en el muestreo por parcelas se encontraron 2.309 individuos, 186 especies y 52 familias. El índice de diversidad de Shannon fue $H^{\prime}=4.35$ nats.ind para una igualdad de $\mathrm{J}^{\prime}=0.83$, lo que indica una alta diversidad florística en el área. El grupo de especies con mayor predominio fue el de especies secundarias tardías y en el análisis multitemporal de la cobertura del suelo se pudo constatar que el $95,8 \%$ es bosque secundario en etapa media de regeneración. Los parámetros dendrométricos de densidad y área basal tuvieron valores cercanos a los encontrados en remanentes de bosques primarios y secundarios en la región amazónica; el ambiente de borde presentó parámetros florísticoestructurales un poco más altos que el ambiente interior, con excepción del parámetro de área basal que fue mayor dentro del fragmento y mediante el análisis de la etapa sucesional y dinámica de la cobertura del suelo.

Palabra clave: Bosques urbanos; Sucesión secundaria; Cobertura del suelo.

\section{Introdução}

O Brasil contém a maior extensão remanescente de florestas tropicais do planeta, com mais de $60 \%$ da floresta amazônica dentro de suas fronteiras (FAO, 2010). Como em outras regiões tropicais, o abandono de áreas e o aumento dos índices de desmatamento levaram ao crescimento de florestas secundárias em todo o país.

Nas últimas três décadas, a área da Amazônia ocupada pela regeneração de florestas secundárias aumentou cinco vezes, de 3 milhões de hectares em 1980 para mais de 15 milhões de ha em 2012 (Aguiar et al., 2016; Jakovac et al., 2016).

Segundo os dados de Leão et al. (2007), até 1986, foram desmatados 597,5 km² de florestas da região metropolitana de Belém, que representavam 50\% de sua área terrestre. No período de 1986 a 2006, ou seja, 20 anos, esta região de Belém perdeu $211,2 \mathrm{~km}^{2}$ de sua cobertura florestal. Esse desmatamento equivale a uma média anual de $10,51 \mathrm{~km}^{2}$, restando até 2007 aproximadamente $369 \mathrm{~km}^{2}(31 \%)$ de florestas remanescentes.

As principais áreas verdes estão situadas nas ilhas e em áreas continentais restritas (terrenos militares, instituições públicas de ensino e pesquisa - Empresa Brasileira de Pesquisa Agropecuária - Embrapa, Museu Paraense Emílio Goeldi MPEG, Universidade Federal do Pará - UFPA, Universidade Federal Rural da Amazônia - UFRA e Unidades de Conservação (Leão et al., 2007).

Os fragmentos florestais urbanos ou próximos às cidades são cada vez mais incomuns, e as diretrizes para sua conservação ou mesmo a importância de sua manutenção como espaços naturais de conservação são dúvidas frequentes. Isso ocorre devido os diferentes estágios de fragmentação decorrentes dos diferentes padrões de desenvolvimento social e econômico nacionais, regionais e locais (Fiszon et al., 2003; Tabarelli et al., 2004; Fearnside, 2006).

Apesar da importância dos fragmentos florestais urbanos para a manutenção da biodiversidade e para o bem-estar humano (Alvey, 2006; Nilon, 2011), a disponibilidade de informações ecológicas em ambientes urbanos ainda é muito limitada. Assim, Marris (2009) destaca que apenas 3\% dos trabalhos científicos sobre essa temática foram publicados nas principais revistas científicas de ecologia na década passada. Isso gera lacunas de informações justamente nas áreas de maior 
necessidade de serviços ambientais para o bem-estar humano, o que limita o subsídio de ações para recuperação e conservação da biota nativa remanescente.

Na Amazônia brasileira, estudos referentes aos fragmentos florestais são poucos, principalmente quando se refere aos fragmentos urbanos (Viana et al., 1997). Contudo, o interesse no estudo das consequências da fragmentação florestal sobre a conservação da biodiversidade tem aumentado desde a década de 90 (Metzger, 1998). A justificativa para tanto, está na constatação de que a maior parte da biodiversidade encontra-se localizada em pequenos fragmentos florestais, pouco estudados e historicamente marginalizados pelas iniciativas conservacionistas (Gradwohl \& Greenberg, 1991).

Considerando o exposto anteriormente é necessário o conhecimento do potencial florístico e estrutural desses remanescentes florestais, sendo para isso fundamental o planejamento inicial sobre a condução do experimento que se deseja aplicar para realizar os levantamentos das informações necessárias.

Na Botânica, dois principais tipos de levantamentos são observados (Watt, 1947): os florísticos, que tratam da diagnose e classificação das comunidades e têm como objetivo verificar quantas e quais espécies estão presentes; e os ecológicos ou fitossociológicos, que têm como finalidade avaliar a dinâmica ou estrutura das comunidades vegetais. Os levantamentos fitossociológicos diferem dos florísticos por utilizarem medidas (tamanho, número de indivíduos, etc.) como parâmetros analíticos, enquadrando-se principalmente em duas categorias: estimativa de medidas ou reconhecimento de padrões (Pillar, 1998).

Em função do acelerado processo de degradação e fragmentação das florestas tropicais em todo o mundo, e a busca de alternativas para o seu manejo e recuperação, há necessidade da utilização de métodos que avaliem o estado de conservação destas florestas. O que se observa na maioria dos estudos relacionados à vegetação de fragmentos florestais urbanos é a grande variação no comportamento das espécies vegetais quando se avalia a riqueza, composição, diversidade e estrutura florística, principalmente quando as características da vegetação são avaliadas em diferentes períodos e/ou pontos da área estudada.

Objetivando a avaliação da importância deste e de outros fragmentos florestais adjacentes, na formulação de estratégias de conservação para esses espaços e na maneira como os mesmos devem ser manejados para que tenham seus serviços ambientais potencializados para a população de Belém, foi feito a caracterização da composição florística, a fitossociologia, os grupos ecológicos e a dinâmica de cobertura do solo da comunidade arbórea do fragmento florestal Capoeira do Black, situado em perímetro urbano da cidade de Belém-PA.

\section{Material e Métodos}

\section{Área de Estudo}

O estudo foi realizado em um fragmento florestal urbano, conhecido por Capoeira do Black (Figura 1), localizado na zona periurbana da cidade de Belém (Watrin \& Homma, 2007). A área é administrada pela Embrapa Amazônia Oriental e compreende, em sua totalidade, um polígono de 8,50 ha com forma predominantemente retangular, limitado entre as latitudes $01^{\circ} 27^{\prime} 00^{\prime}$ 'S e longitude $48^{\circ} 49^{\prime} 00^{\prime}$ 'W, com altitude média de $10 \mathrm{~m}$ acima do nível do mar. 
Figura 1 - Mapa de localização da área de estudo 'Capoeira do Black', em Belém, Pará.

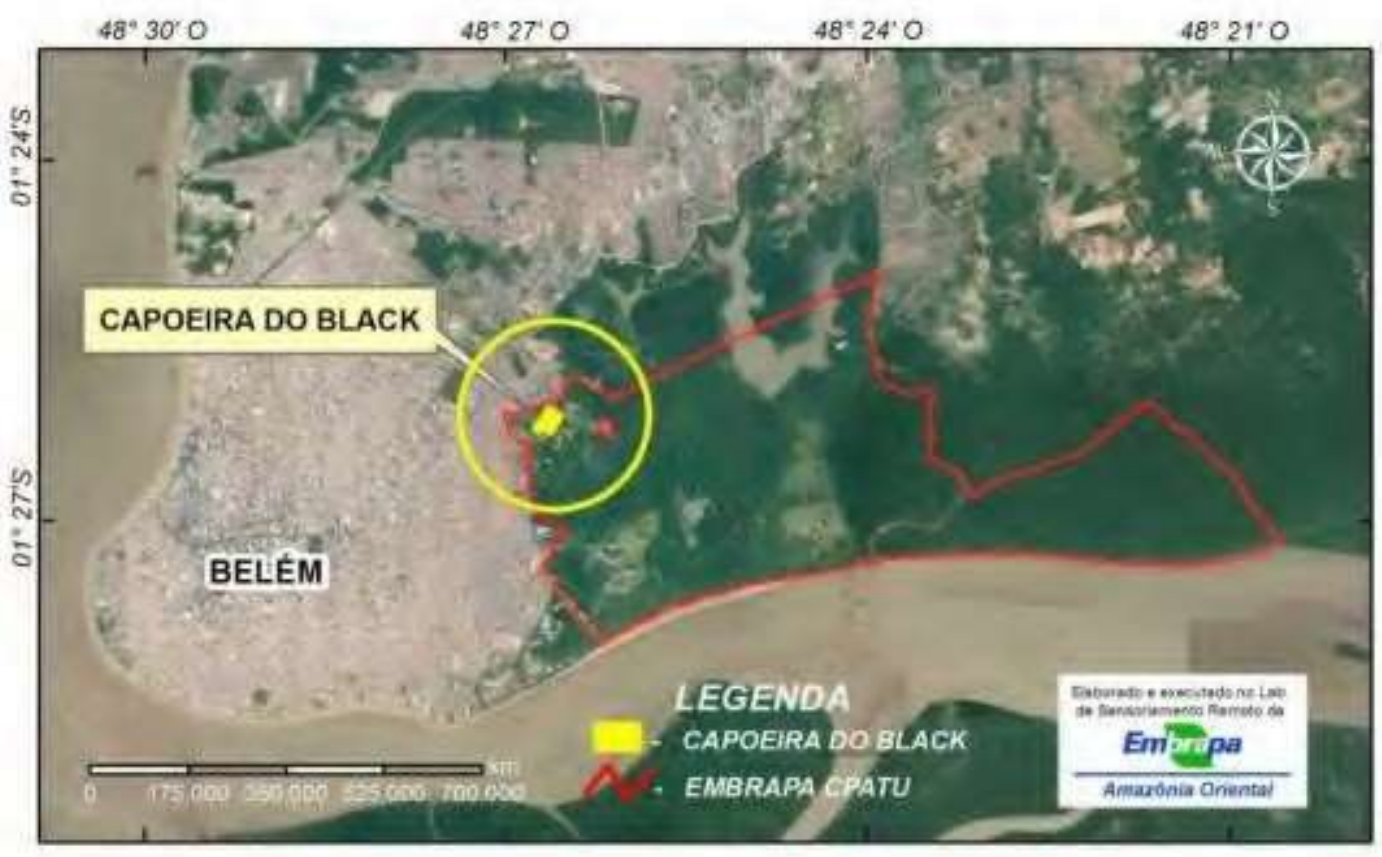

Fonte: Autores (2018).

Segundo dados fornecidos pelo Laboratório de Climatologia da Embrapa Amazônia Oriental - CPATU (2018), o clima da região, de acordo com a classificação de Köppen, é predominantemente Afi, enquadrado como tropical chuvoso, com temperatura anual média em torno de $26,4^{\circ} \mathrm{C}$ e precipitação pluviométrica relativamente abundante durante todo o ano, chegando a $3.000 \mathrm{~mm}$, a uma umidade relativa do ar em torno de $90 \%$.

Os solos predominantes pertencem a uma das seções fisiográficas presentes na área: os terraços aluviais antigos, provavelmente Pleistocênicos (Vieira et al., 1967; Embrapa, 1997). Os terraços aluviais ("terra firme") são formados por sedimentos inconsolidados caoliníticos, dando origem a solos profundos, bem drenados e quimicamente pobres, representados por Latossolo Amarelo Distrófico típico e, em menor proporção, Latossolo Amarelo Distrófico petroplíntico (apenas em uma faixa paralela a Rodovia Murutucu, na face norte da área protegida).

A face norte do polígono em que se localiza a área é limitada pela Estrada da Ceasa (Rodovia Murutucu), sendo as demais definidas por ramais internos pertencentes à malha viária da Embrapa. O vértice de uma das faces sul deste fragmento florestal chega bem próximo do Laboratório de Botânica da instituição Embrapa Amazônia Oriental (Figura 2). 
Figura 2 - Limites da área de estudo e sua inserção na paisagem local.

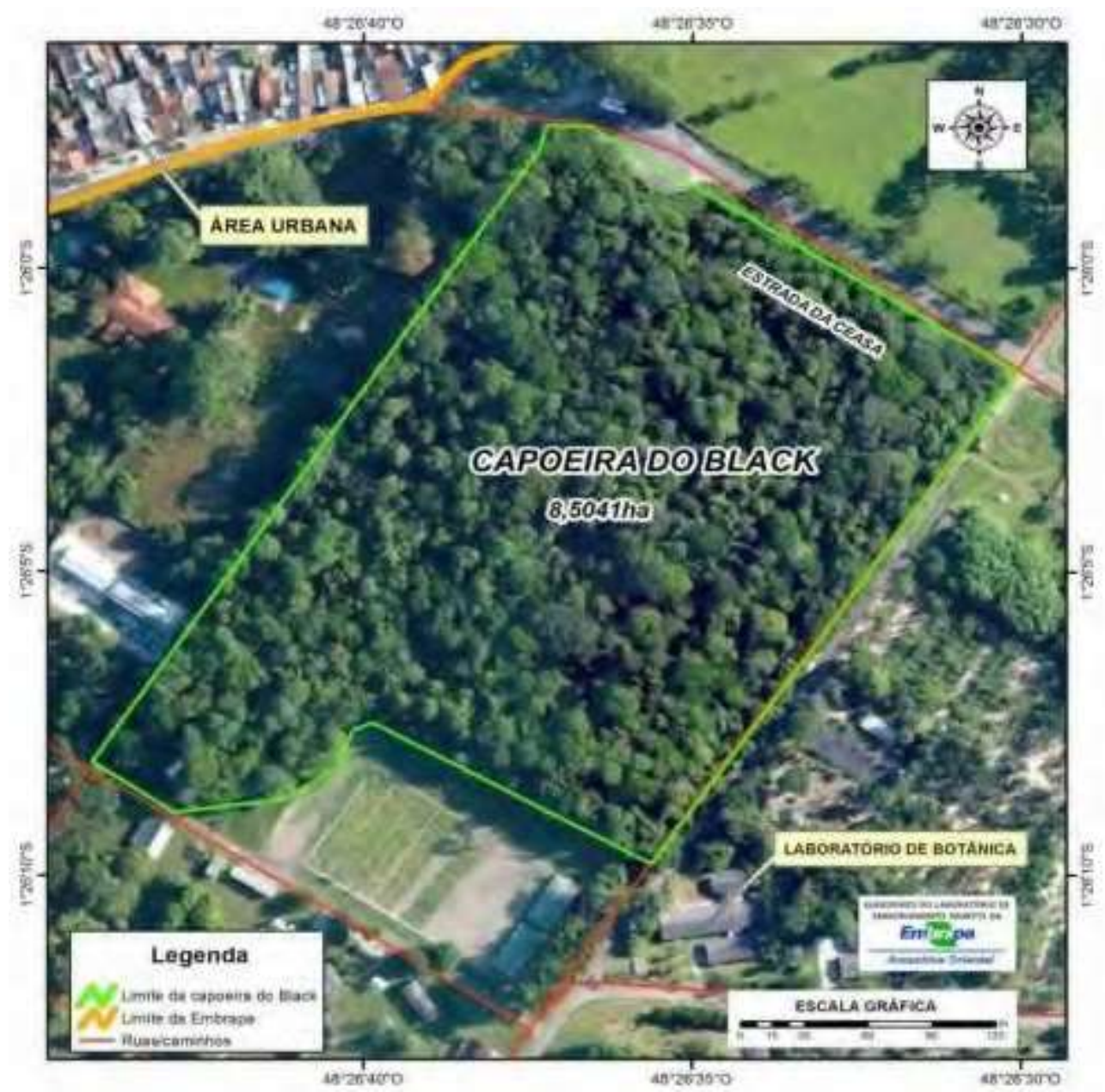

Fonte: Autores (2018).

De acordo com Borges et al. (2007), o fragmento em questão encontra-se em estágio secundário de sucessão ecológica, devido aos distúrbios antropogênicos anteriores. Por estar inserido no contexto de uma área urbana, a antropização é evidente, principalmente nasbordas do fragmento em contato com a estrutura edificante adjacente.

\section{Coleta dos dados}

A coleta de dados para este estudo foi subdividida em duas partes: 1) Inventário Florestal a 100\% de intensidade, realizado no ano de 2016 e 2) Instalação e medição de 8 parcelas permanentes de 50 x 50m no ano de 2017.

Durante os meses de outubro a dezembro de 2016 foi realizado o censo (Inventário Florestal a 100\%) da área onde foram inventariados todos os indivíduos arbóreos e palmeiras. Para a realização deste censo, toda a extensão do fragmento florestal foi subdividida em seis faixas de 250 × $50 \mathrm{~m}$ e a Faixa L (Figura 3), e em seguida mensurados todos os indivíduos com medidas igual ou superior a $15 \mathrm{~cm}$ de diâmetro a altura do peito (DAP), medidos a 1,30 m de altura a partir do nível do solo. 
Figura 3 - Esquema com delimitação das seis faixas $(50$ x 250m) e faixa L utilizadas para a realização do Censo Florestal.
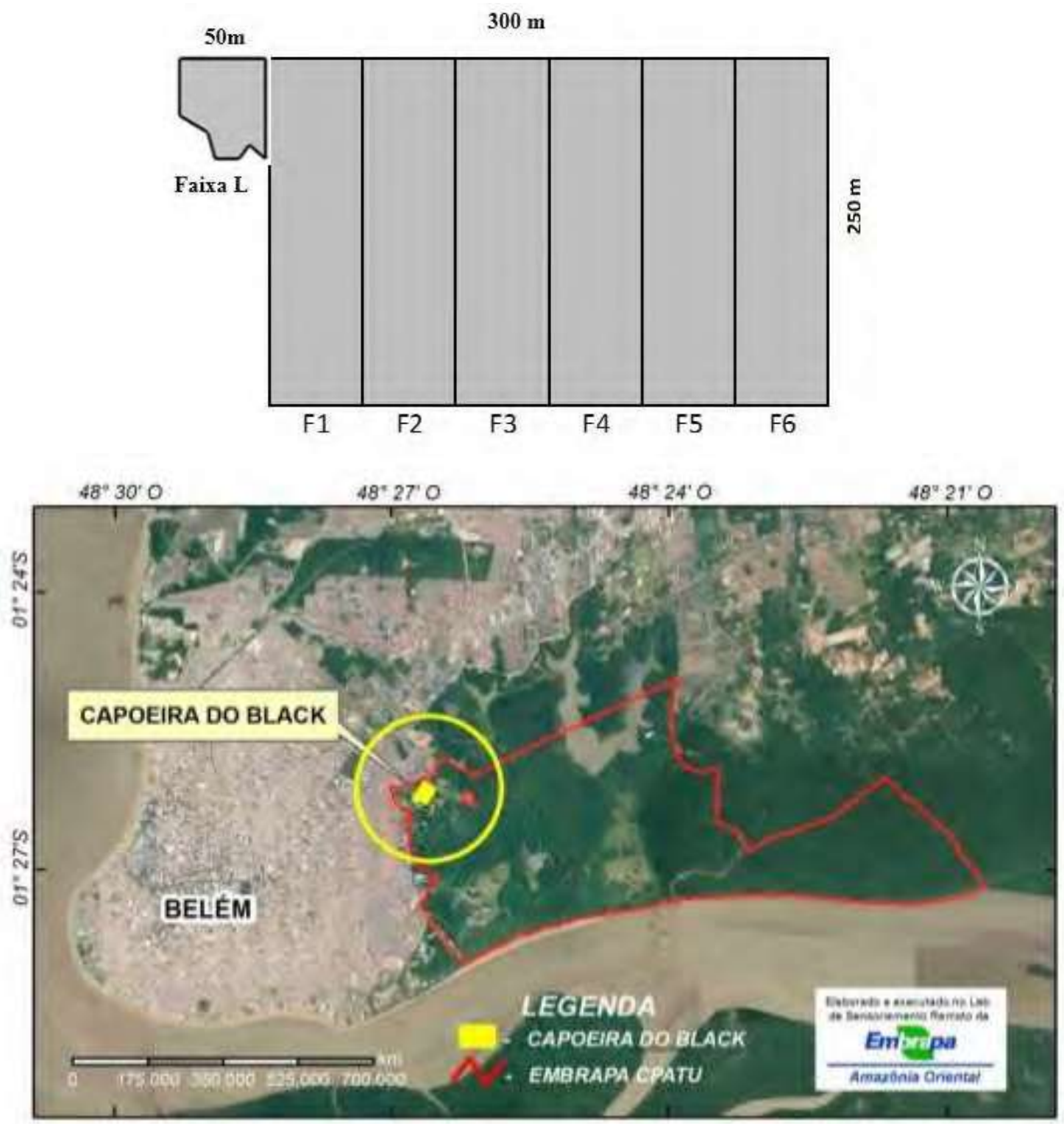

Fonte: Autores (2018).

Todos os indivíduos contemplados pelo critério de inclusão foram identificados em nível de espécie, georreferenciados e enumerados com plaquetas de alumínio em ordem consecutiva conforme a sequência dos inventários nas faixas (Figura 4). 
Figura 4 - Exemplos de alguns dos procedimentos realizados em campo: A - Identificação das espécies; B - Etiquetagem dos indivíduos mensurados.

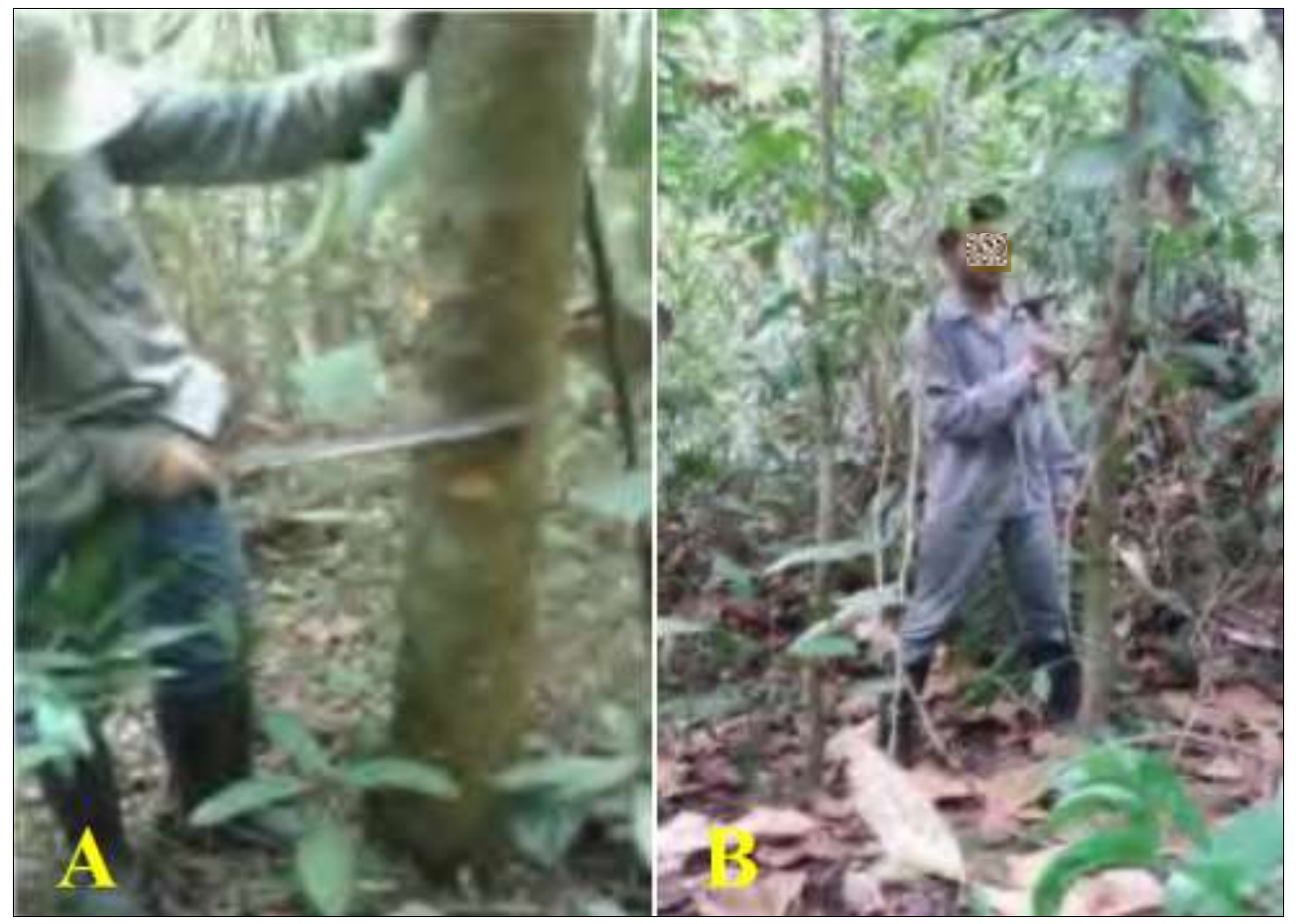

Fonte: Autores (2018).

No ano de 2017, foram alocadas oito parcelas permanentes de 50 x 50m (2500 m²), distribuídas sistematicamente, em dois estratos, de forma a amostrar e a comparar duas diferentes áreas da comunidade: o ambiente de borda e o ambiente de interior do fragmento florestal. Desse total, 4 parcelas de 50 x $50 \mathrm{~m}$ foram alocadas em cada ambiente, perfazendo uma área de um hectare por ambiente, totalizando dois hectares de amostragem na comunidade. Foram incluídos na amostragem todos os indivíduos arbóreos vivos com diâmetro DAP $\geq 5 \mathrm{~cm}$, medido a $1,30 \mathrm{~m}$ acima do solo. A área amostrada corresponde a $23,5 \%$ da área total do fragmento florestal (Figura 5).

Todas as espécies foram identificadas em campo por parabotânicos e, espécies de difícil identificação ou que se tinha alguma dúvida, foram coletadas e identificadas por comparação com espécies existentes no acervo do Herbário IAN, Embrapa Amazônia Oriental. Para tal, utilizou-se o sistema de classificação Angiosperm Phylogeny Group - APG IV, cujas nomenclaturas botânicas foram devidamente confirmadas na base de dados Flora do Brasil - Reflora (2020). Os dados obtidos em campo foram processados em software específico para análise dos dados florísticos, o Amasoft MFT (Monitoramento de Florestas Tropicais). 
Figura 5 - Esquema de alocação das parcelas permanentes, ano de 2017: A - Arranjo das quadras e distinção entre área de Borda e Interior do fragmento e; B - Disposição aleatória das oito parcelas permanentes de monitoramento (área hachurada em preto).
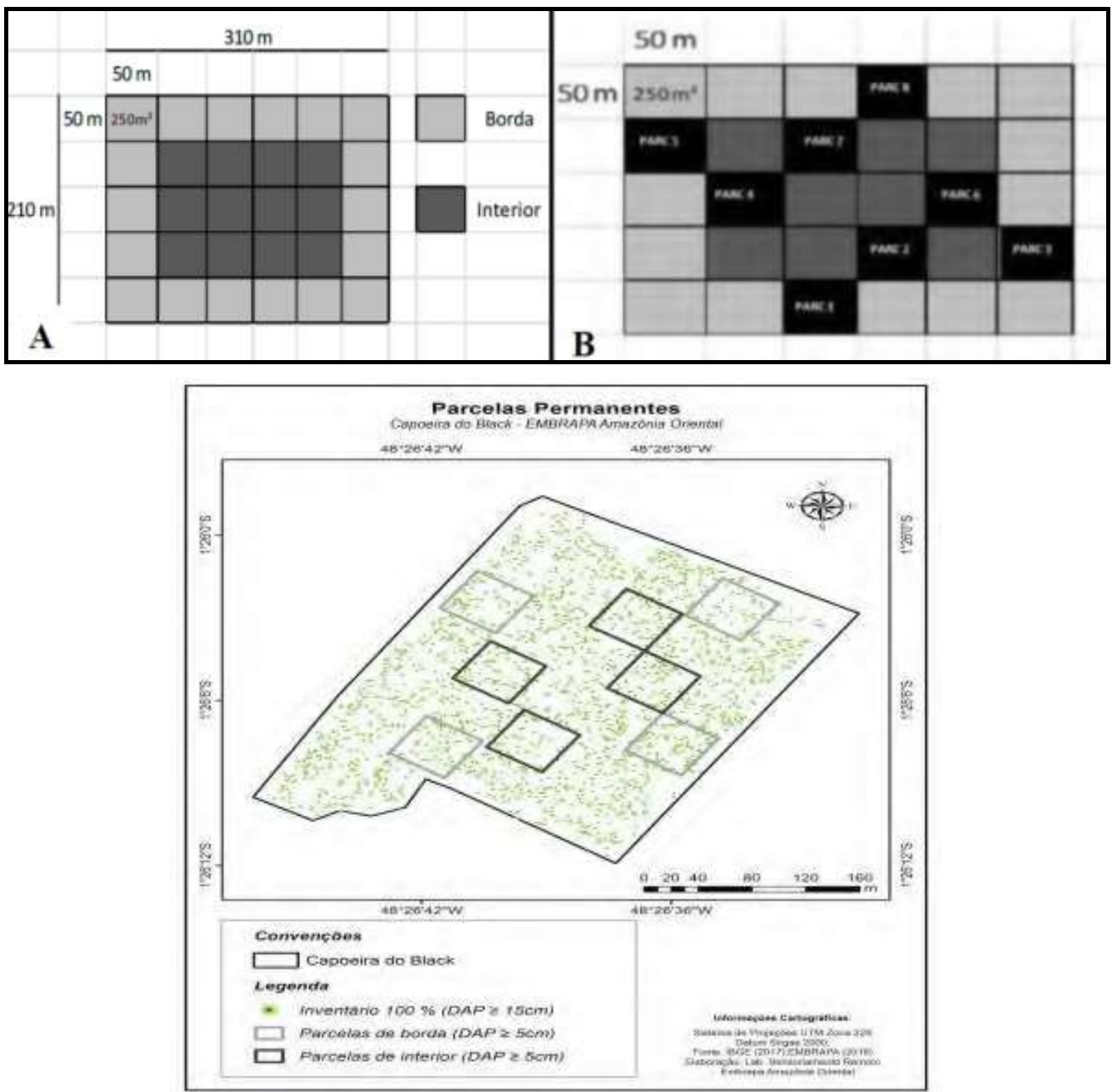

Fonte: Lab. Sensoriamento Remoto - Embrapa Amazônia Oriental.

A Tabela 1 mostra um resumo de como se procedeu as mensurações na área, de acordo com o ano de medição, tamanho amostral e número de parcelas avaliadas. 
Tabela 1 - Medições na área da Capoeira do Black: Ano, unidade amostral, número de UA's, amostra total e intensidade amostral.

\begin{tabular}{|c|c|c|c|c|}
\hline Ano & Unidade Amostral & $\begin{array}{l}\text { Número } \\
\text { de UA's }\end{array}$ & Amostra Total & $\begin{array}{c}\text { Intensidade } \\
\text { Amostral (\%) }\end{array}$ \\
\hline 2016 & - & - & $8,5 \mathrm{ha}(250 \mathrm{~m} \times 300 \mathrm{~m})$ & 100,0 \\
\hline 2017 & $\begin{array}{c}0,25 \text { ha }(50 \mathrm{~m} \times 50 \\
\mathrm{m})\end{array}$ & 8 & 2,0 há $(8 \times 50 \mathrm{~m} \times 50 \mathrm{~m})$ & 23,5 \\
\hline
\end{tabular}

Onde: Ano $=$ Ano de medição

UA's = Unidades amostrais

Fonte: Autores (2018).

\section{Análise dos dados \\ Curva espécie-área}

Para avaliar a suficiência do número de parcelas amostrais neste estudo, foi utilizado o método de curva espécie-área, adicionando-se o número acumulado de espécies novas não amostradas por área. O ponto onde a curva tende a estabilizar- se representa a área mínima de amostragem florística (Cain et al. 1956). O cálculo para a análise da curva, com intervalo de confiança a 95\% de probabilidade e estimativa de riqueza, sendo realizado no programa Microsoft Excel 2013.

A análise da curva constou de figuras relacionando o esforço amostral (número de parcelas amostradas) cumulativo (eixo X) com o número cumulativo de espécies amostradas (eixo Y). Nesse método, a área amostral é suficiente para indicar se ocorreu a estabilização do número de espécies por área.

Em resumo, a curva espécie-área representa o número acumulado de espécies registradas, plotadas em um gráfico, que indica qual foi a quantidade de esforço empregado para se inventariar a área. A curva de acúmulo atinge uma assíntota horizontal quando a maioria das espécies de uma área já foi coletada (Colwell \& Coddington, 1994).

\section{Composição Florística e Estrutura Fitossociológica do Fragmento}

A flora da comunidade vegetal foi caracterizada através da distribuição dos indivíduos, agrupados nas diversas famílias, gêneros e espécies de toda a extensão da área e dentre as unidades amostrais. A riqueza florística foi analisada por meio do número de espécies e famílias botânicas amostradas.

Foram calculadas as variáveis fitossociológicas como densidade, frequência e dominância, absolutas e relativas, assim como os índices de valor de importância ecológica das famílias e espécies (Cottan \& Curtis, 1956; Mueller-Dombois \& Ellenberg, 1974) e o índice de cobertura das espécies (Matteuci \& Colma, 1982).

Realizou-se a distribuição dos indivíduos por classe de diâmetro (DAP), dividida em cinco classes com $10 \mathrm{~cm}$ de amplitude, de forma a indicar se a floresta está na sua dinâmica normal de crescimento. A estrutura diamétrica foi avaliada pelo computo da área total e pela amostragem das parcelas permanentes. Tais variáveis foram calculadas seguindo os métodos expostos no Quadro 1. 
Quadro 1 - Equações empregadas nos cálculos das variáveis fitossociológicas e estruturais da vegetação do fragmento florestal Capoeira do Black, Belém-PA.

\begin{tabular}{|c|c|c|}
\hline Variável & Equação & Autor \\
\hline $\begin{array}{l}\text { Frequência absoluta } \\
\qquad \text { (FA) }\end{array}$ & $\begin{array}{l}\qquad F A i=\left(\frac{u i}{u t}\right) * 100 \\
\text { FAi }=\text { frequência absoluta da i-ésima espécie, } \\
\text { dada em percentagem;ui }=\text { número de unidades } \\
\text { de amostragem em que a i-ésima espécie está } \\
\text { presente;ut = número total de unidades de } \\
\text { amostragem; }\end{array}$ & $\begin{array}{c}\text { Mueller-Dombois \& } \\
\text { Ellenberg (1974). }\end{array}$ \\
\hline $\begin{array}{l}\text { Frequência relativa } \\
\qquad(\mathrm{FR} \%)\end{array}$ & $\begin{array}{l}\qquad F R i=\left(F A i / \sum_{i=1} F A i\right) * 100 \\
\begin{array}{l}\text { FRi }=\text { frequência relativa da i-ésima espécie, em } \\
\text { percentagem; } \\
\mathrm{p}=\text { número total de espécies amostradas. }\end{array}\end{array}$ & $\begin{array}{c}\text { Mueller-Dombois \& } \\
\text { Ellenberg (1974). }\end{array}$ \\
\hline $\begin{array}{c}\text { Densidade absoluta } \\
\text { (DA) }\end{array}$ & $\begin{array}{l}\qquad D A i=\frac{n i}{A} \\
\mathrm{i}=1 \ldots \text { p espécies; } \\
\mathrm{DAi}=\text { densidade absoluta da i-ésima espécie; } \\
\text { ni = número de indivíduos amostrados da i- } \\
\text { ésima espécie; } \\
\mathrm{A}=\text { área em hectares da unidade de amostragem } \\
\text { ou da amostra; }\end{array}$ & $\begin{array}{c}\text { Mueller-Dombois \& } \\
\text { Ellenberg (1974). }\end{array}$ \\
\hline $\begin{array}{c}\text { Densidade relativa } \\
\text { (DR\%) }\end{array}$ & $\begin{array}{c}D R i=\left(D A i / \sum_{i=1}^{p} D A i\right) * 100 \\
\begin{array}{l}\text { DRi }=\text { densidade relativa da i-ésima espécie; } \\
\mathrm{p}=\text { número total de espécies amostradas. }\end{array}\end{array}$ & $\begin{array}{c}\text { Mueller-Dombois \& } \\
\text { Ellenberg (1974). }\end{array}$ \\
\hline $\begin{array}{c}\text { Dominância absoluta } \\
\text { (DoA) }\end{array}$ & $\begin{array}{l}\qquad D o A i=G i / a \\
\mathrm{i}=1 \ldots \mathrm{p} \text { espécies; } \\
\mathrm{DoA}=\text { dominância absoluta da } \mathrm{i} \text {-ésima espécie, } \\
\mathrm{em}^{2} \text {.há }{ }^{\prime} \text {; } \\
\mathrm{Gi}=\text { área basal da i-ésima espécie, em } \mathrm{m}^{2} . \mathrm{ha}^{1} ; \\
\mathrm{a}=\text { área em hectares da unidade de amostragem } \\
\text { ou da amostra; }\end{array}$ & $\begin{array}{c}\text { Mueller-Dombois \& } \\
\text { Ellenberg (1974). }\end{array}$ \\
\hline $\begin{array}{c}\text { Dominância relativa } \\
\text { (DoR\%) }\end{array}$ & $\begin{array}{l}\qquad D o R=\left(\frac{D o A i}{\sum_{i=1}^{p} D o A i}\right) * 100 \\
\text { DoRi = dominância relativa da i-ésima espécie, } \\
\text { em percentagem; } \\
\mathrm{p}=\text { número total de espécies amostradas. }\end{array}$ & $\begin{array}{l}\text { Mueller-Dombois \& } \\
\text { Ellenberg (1974). }\end{array}$ \\
\hline $\begin{array}{l}\text { Índice de Valor de } \\
\text { Importância (IVIsp) }\end{array}$ & $\begin{array}{l}I V I i=F R i+D R i+D o R i ; \\
I V I \%=\frac{D R i+D o R i+F R i}{3} \\
\text { IVIi }=\text { indice do valor de importância para } \mathrm{i}- \\
\text { ésima espécie. }\end{array}$ & $\begin{array}{l}\text { Cottam \&Curtis (1956); } \\
\text { Mueller-Dombois \& } \\
\text { Ellenberg (1974). }\end{array}$ \\
\hline
\end{tabular}




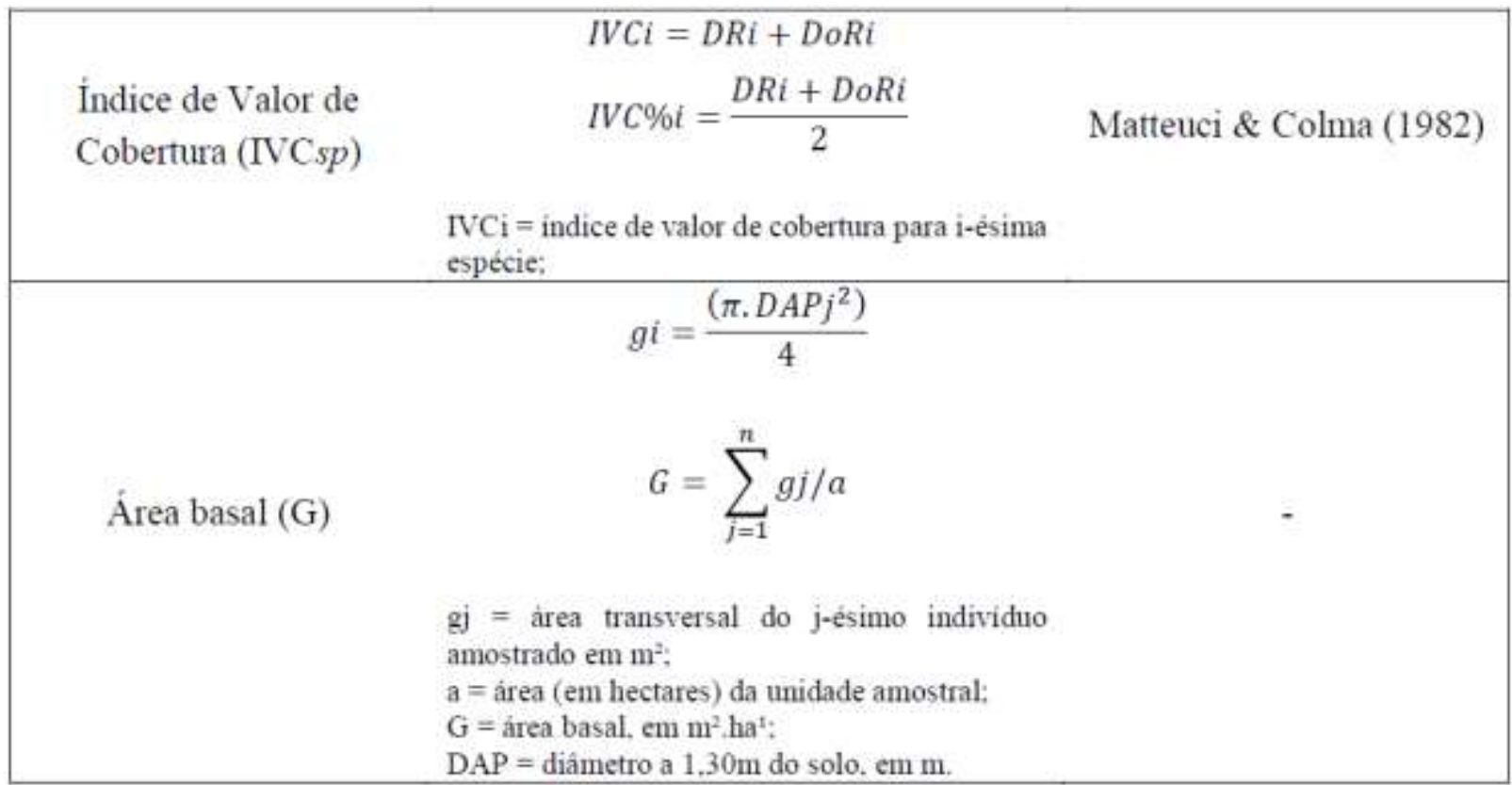

Fonte: Autores (2018).

\section{Estimativas de Diversidade, Similaridade e Equabilidade}

A diversidade de espécies nas unidades amostrais foi medida pelo Índice de Diversidade de Shannon (H’), que considera a transformação logarítmica (base natural) da densidade das espécies, sendo influenciado pelas espécies de menor densidade na amostra (Magurran, 2004). Os valores de H' situam-se entre 1,3 e 3,5 nats ind ${ }^{-1}$, podendo alcançar valores mais altos, indicando diversidade bastante elevada, como é o caso de florestas tropicais.

Para avaliar a similaridade florística-estrutural (IVI das espécies por ambiente) entre as unidades amostrais do fragmento foi utilizado o Índice de Bray-Curtis (BC) que é expresso como uma proporção de similaridade ou dissimilaridade (distância) na abundância das espécies. Em qualquer um dos casos, seus valores vão de um mínimo de zero a um máximo de um. Essa padronização no intervalo entre um e zero facilita a interpretação e comparação (Bray \& Curtis, 1957).

Por sua vez, o Índice de equabilidade de Pielou (J') indica a uniformidade da distribuição dos indivíduos entre as espécies, e sua amplitude de valores vai de zero até 1 (uniformidade máxima) (Pielou, 1966).

Com o intuito de avaliar as possíveis diferenças quanto aos parâmetros de composição e estrutura da vegetação arbórea na comunidade, todas as análises de riqueza florística, diversidade, similaridade e equabilidade foram aplicadas para correlacionar os ambientes (borda-interior) do fragmento florestal (Quadro 2). Para tal, foram realizadas com auxílio do software Excel ${ }^{\circledR}$. 
Quadro 2 - Equações utilizadas nos cálculos dos índices de diversidade, similaridade e equabilidade.

\begin{tabular}{|c|c|c|}
\hline Índice & Equação & Autor \\
\hline $\begin{array}{c}\text { Índice de } \\
\text { Diversidade } \\
\text { Shannon-Weaver } \\
\text { (H') }\end{array}$ & $\begin{array}{l}\qquad H^{\prime}=-\sum \frac{n i}{N} \cdot \ln \frac{n i}{N} \\
\mathrm{H}^{\prime}=\text { Índice de Shannon, } \\
\text { ni = número de indivíduos amostrados da } \\
\text { iésima espécie; } \mathrm{N}=\text { número total de indivíduos } \\
\text { amostrados; e } \ln =\text { logaritmo neperiano. }\end{array}$ & $\begin{array}{l}\text { Felfili e Rezende } \\
\qquad(2003)\end{array}$ \\
\hline $\begin{array}{c}\text { Índice de } \\
\text { Similaridade } \\
\text { Bray-Curtis (BC) }\end{array}$ & $\begin{array}{l}\qquad B C=\sum \frac{(X i j-X i k)}{(X i j+X i k)} \\
\text { Xij = frequência de ocorrência da espécie i no } \\
\text { ambiente } \mathrm{j} \text {; } \\
\text { Xik = frequência de ocorrência da espécie i no } \\
\text { ambiente } \mathrm{K} ; \\
\mathrm{BC}=\text { similaridade de Bray-Curtis.; }\end{array}$ & Bray e Curtis (1957) \\
\hline $\begin{array}{c}\text { Índice de } \\
\text { Equabilidade (J') }\end{array}$ & $\begin{array}{l}\qquad J^{\prime}=\frac{H^{\prime}}{\ln S} \\
\mathrm{~J}^{\prime}=\text { índice em \% de equabilidade de Pielou } \\
\text { da comunidade; } \\
\mathrm{H}^{\prime}=\text { índice de diversidade de Shannon- } \\
\text { Weaver da comunidade; } \\
\mathrm{S}=\text { número total de espécies amostradas; e ln } \\
=\text { logaritmo neperiano. }\end{array}$ & Pielou (1966) \\
\hline
\end{tabular}

Fonte: Autores (2018).

\section{Estágio Sucessional da Vegetação}

Para análise do estado de conservação, estudou-se o estágio sucessional do fragmento, por intermédio da identificação do grupo ecológico das espécies (Budowski, 1965).

Estas foram identificadas como pioneiras $(\mathrm{P})$, secundárias iniciais $(\mathrm{Si})$, secundárias tardias $(\mathrm{St})$ e climácicas $(\mathrm{CL})$, sendo que o predomínio de um dos grupos foi utilizado para definir o estágio sucessional do fragmento, metodologia utilizada também por outros autores em estudos dessa natureza (Dislich et al., 2001). A classificação das espécies em grupos ecológicos baseou-se também nos trabalhos de Oliveira-Filho (1994) e Amaral et al., (2009), modificada para esse estudo com base em revisões bibliográficas e observações em campo. As espécies que não foram encontradas referências na literatura, foram agrupadas na categoria de não determinadas (ND).

\section{Análise Temporal da Cobertura do Solo}

A análise do uso e cobertura do solo por meio de produtos e técnicas de geoprocessamento, técnica útil ao planejamento e administração da ocupação ordenada e racional do meio físico, possibilitou avaliar e monitorar mudanças na vegetação ao longo do tempo.

Para a análise dos mapas de cobertura da terra foi utilizado o Software ArcGIS, versão 10.1, a partir da análise de imagens digitais do sensor Landsat, órbita/ ponto 223/61. A análise foi realizada considerando as seguintes datas datas: 
27/07/1984, 26/06/1996, 31/07/2000, 06/08/2005 e 14/04/2010, (bandas TM 3, 4 e 5); 22/11/2015 e 27/09/2018 (bandas OLI $4,5$ e 6$)$.

Foi utilizado o método ISODATA de classificação que é, provavelmente, o mais conhecido e é descrito como um meio efetivo de interpretação de imagens de sensoriamento remoto assistida por computador.

Essa técnica de classificação identifica padrões típicos nos níveis de cinza. Esses padrões são então classificados efetuando-se visitas de reconhecimento a alguns poucos exemplos escolhidos para determinar sua interpretação.

Em razão da técnica usada nesse processo, os padrões são geralmente referidos como "clusters" (agrupamentos ou nuvens). Neste tipo de classificação, as classes são determinadas pela análise de tais agrupamentos ("cluster analysis").

Podemos dizer que, no caso das classificações não-supervisionadas, quanto maior a heterogeneidade das amostras, maior a certeza de que todas as classes possíveis estarão representadas.

Os pixels na área de estudo foram, então, submetidos a algoritmos de agrupamento ("clustering"), que determinam o agregamento natural dos dados, considerando sua distribuição num espaço de $\mathbf{n}$ dimensões (no caso, bandas espectrais). A determinação do número de classes para as quais o computador deve calcular o algoritmo de grupamento foi o padrão, ou seja, três classes.

Por fim, foi definido o número de interações (repetições do processo), que a cada interação, recalculam-se e reclassificam- se os pixels, considerando-se os novos valores médios. As classes de uso e cobertura do solo avaliadas estão mencionadas e descritas na Tabela 2.

Tabela 2 - Classificação de uso e cobertura do solo do fragmento florestal Capoeira do Black.

\begin{tabular}{lllll}
\hline \multicolumn{1}{c}{ CLASSE } & \multicolumn{4}{c}{ DESCRIÇÃO } \\
\hline Solo Exposto & $\begin{array}{l}\text { Acopla os solos descobertos, sem a } \\
\text { presença de vegetação }\end{array}$ \\
$\begin{array}{l}\text { Floresta Secundária - Estágio Inicial de } \\
\text { Regeneração }\end{array}$ & $\begin{array}{l}\text { Floresta jovem, processo } \\
\text { sucessão }\end{array}$ & inicial de \\
$\begin{array}{l}\text { Floresta Secundária - Estágio médio de } \\
\text { regeneração }\end{array}$ & $\begin{array}{l}\text { Floresta em transição, } \\
\text { intermediário de sucessão }\end{array}$ & \\
& & & \\
\end{tabular}

Fonte: Autores (2018).

\section{Resultados e Discussão}

\section{Curva Espécie-área}

A curva espécie-área, expressada junto com a linha de tendência logarítmica (Figura 6), apresentou uma tendência a estabilização quando atingiu entre 1,75 a 2 ha de área na amostragem de 2017. Com esta amostragem de dois hectares foram detectadas 186 espécies, o que representa a riqueza florística do fragmento florestal em sua totalidade, conforme universo de 171 espécies encontradas no inventário a $100 \%$ de intensidade. 
Figura 6 - Curva espécie-área considerando os indivíduos arbóreos para o inventário amostral de oito parcelas permanentes, no ano de 2017.

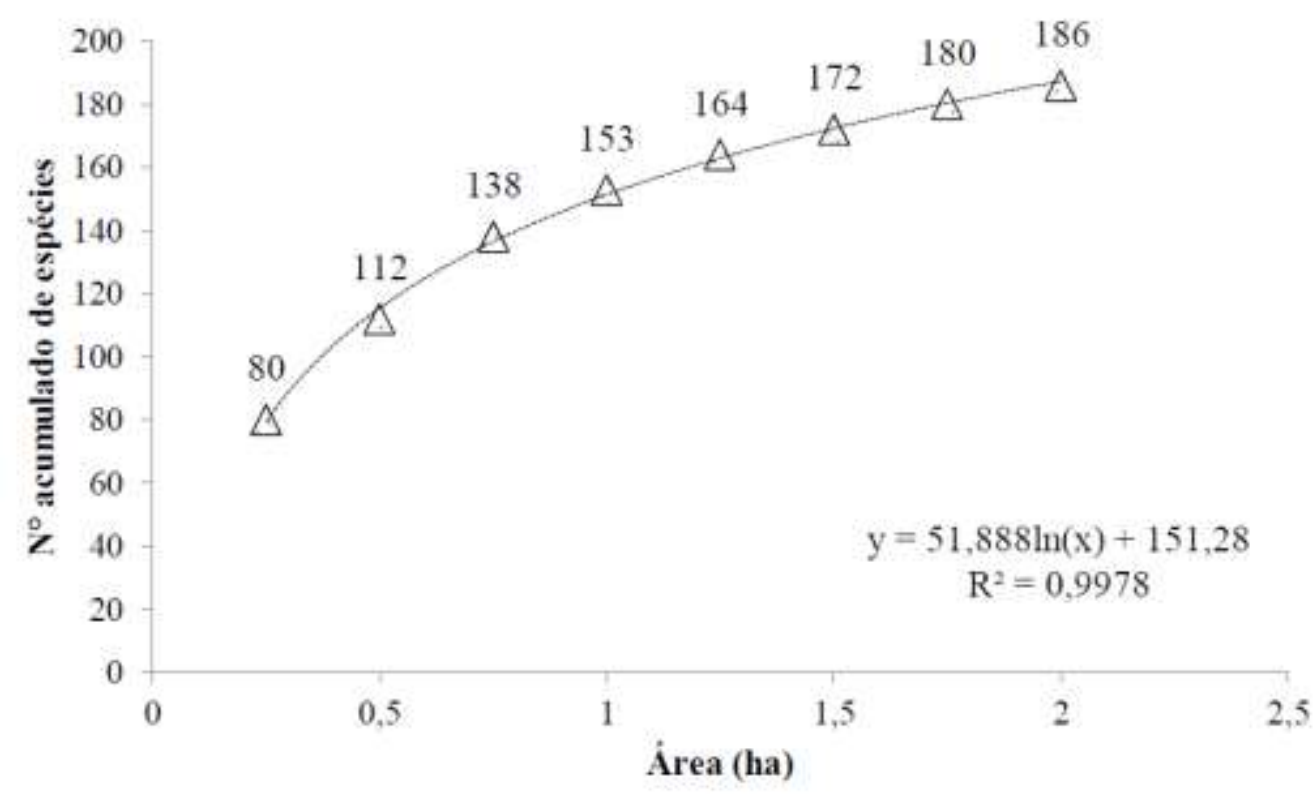

Fonte: Autores (2018).

De acordo com Caine Castro (1959) e Mueller-Dombois e Ellemberg (1974), em florestas tropicais não há ponto de estabilização da curva em termos do número de espécies que são observadas à medida que se aumenta o tamanho da amostra.

Carim et al. (2007) em um trabalho que discute sobre a riqueza de espécies, estrutura e composição florística de uma floresta secundária na Amazônia, encontraram respostas semelhantes a deste estudo, cuja avaliação ocorreu em uma área de um hectare, com medição dos indivíduos com DAP $\geq 5 \mathrm{~cm}$, onde a curva também não apresentou uma estabilização clara, muito embora tenham percebido uma tendência a uma assíntota.

Em se tratando de vegetação secundária, onde há uma grande expansão de ocupação de área, o que vem gerando gradientes ambientais (borda-interior), este comportamento é de certa forma esperado, visto o processo dinâmico de sucessão vegetal inerente ao ambiente. Um novo grupo de espécies poderia se estabelecer devido às condições ambientais da área, o que propicia o recrutamento de novas espécies.

\section{Parâmetros fitossociológicos}

\section{Famílias}

No ordenamento das dez famílias com maior abundância na área, a Fabaceae ganha destaque tanto no censo quanto na amostragem por parcelas. Seis famílias foram semelhantes nas duas ocasiões, com exceção das famílias Simaroubaceae, Urticaceae, Araliaceae e Peraceae (Censo), e Moraceae, Achariaceae, Lecytidaceae e Clusiaceae (Amostragem PP's) que se presenciam em pelo menos um dos períodos (Tabela 3). 
Tabela 3 - Comparação das ordens de distribuição das famílias com maior abundância obtida para indivíduos com DAP $\geq 5$ cm (Amostragem PP's) e para indivíduos com DAP $\geq 15 \mathrm{~cm}$ (Censo) avaliadas no fragmento florestal Capoeira do Black, BelémPA.

\begin{tabular}{|c|c|c|c|c|}
\hline \multicolumn{5}{|c|}{$\mathrm{N}^{\circ}$ ind/ha } \\
\hline Ordem & Família & Censo (2016) & Família & $\begin{array}{l}8 \text { PP's } \\
\text { (2017) }\end{array}$ \\
\hline $1^{\circ}$ & Fabaceae & 48,1 & Fabaceae & 244,5 \\
\hline $2^{\circ}$ & Arecaceae & 27,2 & Arecaceae & 145,0 \\
\hline $3^{\circ}$ & Lauraceae & 24,5 & Lauraceae & 55,5 \\
\hline $4^{\circ}$ & Anacardiaceae & 20,7 & Anacardiaceae & 53,0 \\
\hline $5^{\circ}$ & Simaroubaceae & 12,7 & Simaroubaceae & 48,0 \\
\hline $6^{\circ}$ & Urticaceae & 10,8 & Urticaceae & 47,0 \\
\hline $7^{\circ}$ & Araliaceae & 10,5 & Achariaceae & 43,0 \\
\hline $8^{\circ}$ & Annonaceae & 8,8 & Annonaceae & 40,5 \\
\hline $9^{\circ}$ & Peraceae & 8,2 & Peraceae & 36,5 \\
\hline \multirow[t]{4}{*}{$10^{\circ}$} & Nyctaginaceae & 7,6 & Nyctaginaceae & 35,5 \\
\hline & Subtotais (10) & $179,2(68,2 \%)$ & Subtotais (10) & $748,5(64,8 \%)$ \\
\hline & Outras (41) & $83,7(31,8 \%)$ & Outras (41) & $406,0(35,2 \%)$ \\
\hline & Total (51) & 262,9 & Total (51) & $1.154,5$ \\
\hline
\end{tabular}

$\mathrm{N}^{\mathrm{o}}$ Ind/ha = número de indivíduos por hectare amostrados por família em cada período de mensuração.

Fonte: Autores (2018).

De modo geral, Fabaceae é a família que se destaca na maioria dos levantamentos fitossociológicos realizados na Amazônia, tanto em florestas naturais primárias, quanto nas florestas secundárias, inclusive para áreas em processo de sucessão secundária, conforme mostra Coelho et al. (2013) e Vale et al. (2014). Melo (2004) avaliando a florística, a fitossociologia e a dinâmica de duas florestas secundárias antigas, com idades aproximadas e históricos de uso distintos no Nordeste Paraense também encontra a família Fabaceae como sendo a de maior destaque.

Amaral et al. (2009) estudando a flora arbórea de diferentes fragmentos florestais da região metropolitana de Belém, verificaram que as famílias Fabaceae e Lauraceae estão entre as mais abundantes nestes fragmentos, fato semelhante ao que ocorreu neste estudo.

\section{Espécies}

\section{Índice de valor de importância}

Na Figura 7, estão relacionadas as dez espécies mais importantes em relação ao IVI para a amostragem de 2017 na área de estudo. Essas espécies juntas perfazem um total de 38,4\% do índice de valor de importância, o que demonstra que um conjunto de poucas espécies dominam a área. 
Figura 7 - Valores de IVI para as principais espécies encontradas na amostragem realizada em 2017 na Capoeira do Black, Belém, PA.
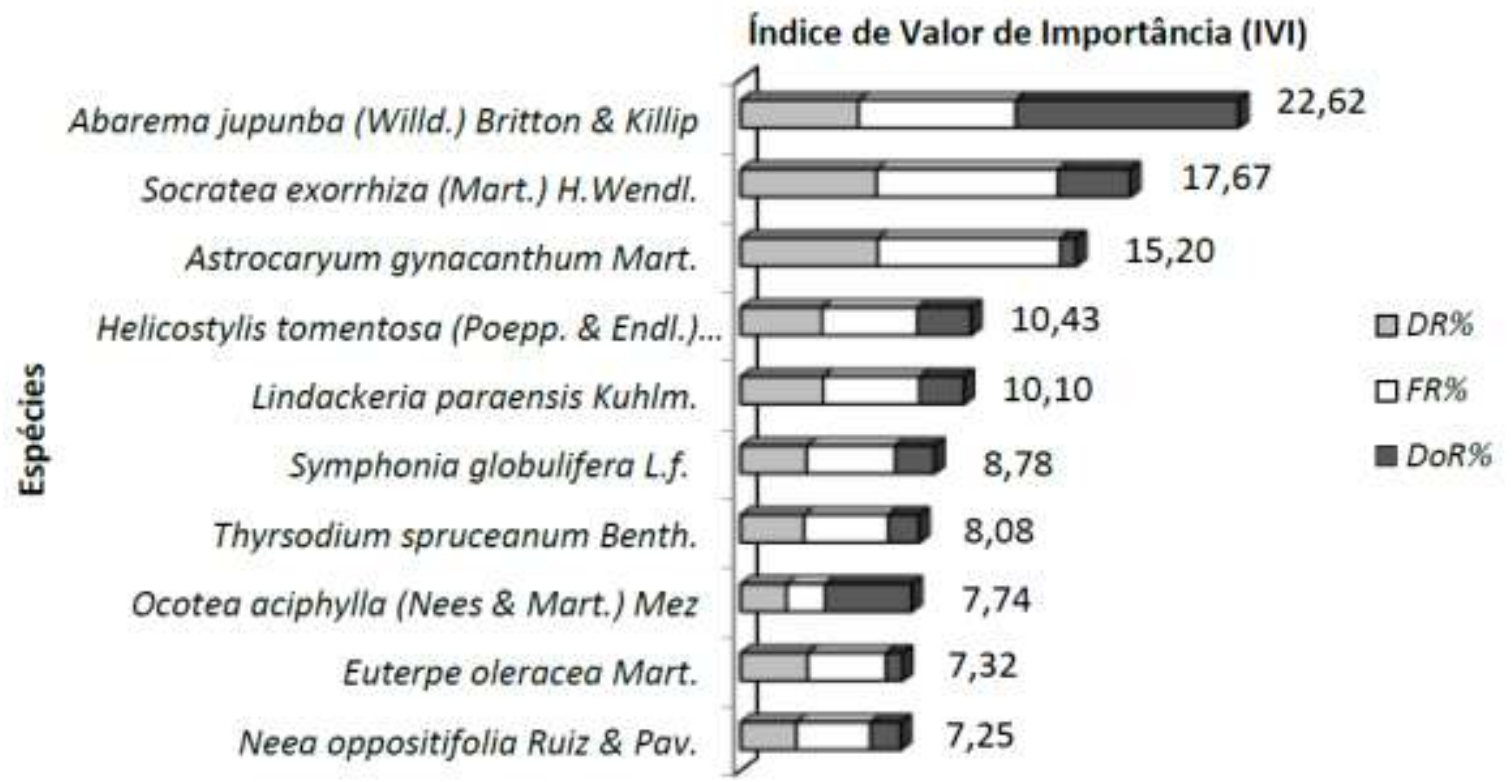

Fonte: Autores (2018).

\section{a) Densidade}

$\mathrm{Na}$ Tabela 4, estão apresentados os valores de densidade e área basal para o censo e para a amostragem de 2017, sob o nível de inclusão de diâmetro a altura do peito (DAP) de cada inventário.

Tabela 4 - Parâmetros dendrométricos de área basal (G) e número de indivíduos (Ni) por hectare entre as diferentes medições, amostragens e níveis de inclusão de DAP na área da Capoeira do Black.

$\mathrm{DAP} \geq 5 \mathrm{~cm} \quad \mathrm{DAP} \geq 15 \mathrm{~cm}$ DAP $\geq 5 \mathrm{~cm} \mathrm{DAP} \geq 15 \mathrm{~cm}$

\begin{tabular}{|c|c|c|c|c|c|c|}
\hline Mediçōes & Amostragem & Área (ha) & $G\left(m^{2} \cdot h a^{1}\right)$ & $G\left(m^{2} \cdot h a^{1}\right)$ & Ni.ha ${ }^{-1}$ & Ni.ha $^{-1}$ \\
\hline 2016 & Censo $(250 \times 300 \mathrm{~m})$ & 8,5 & - & 18,54 & - & 254,59 \\
\hline 2017 & 8 PP's $(50 \times 50 \mathrm{~m})$ & 2 & 23,20 & 18,03 & 1154,5 & 281 \\
\hline
\end{tabular}

Fonte: Autores (2018).

Observou-se que para as duas ocasiões de amostragem, tanto para o censo quanto para o inventário das oito parcelas permanentes, os valores de número de indivíduos por hectare e área basal apresentaram valores aproximados, sendo um pouco superior na amostragem das parcelas devido à inclusão dos indivíduos abaixo de $15 \mathrm{~cm}$ de DAP, o que contribui para o aumento da densidade e da dominância da área.

Na Tabela 5, são apresentados os valores absolutos do número de indivíduos e número de espécies na área. 
Tabela 5 - Esforço amostral e critérios de inclusão utilizados nos dois inventários realizados no fragmento florestal Capoeira do Black, Região Metropolitana de Belém (PA).

\begin{tabular}{cccccc}
\hline Medição & $\begin{array}{c}\text { Área } \\
\text { amostrada } \\
\text { (ha) }\end{array}$ & Unidade amostral & $\begin{array}{c}\text { Critério de } \\
\text { inclusão }\end{array}$ & $\begin{array}{c}\mathbf{N}^{\circ} \text { de } \\
\text { Individuos }\end{array}$ & $\begin{array}{c}\mathbf{N}^{\text {de }} \\
\text { Espécies }\end{array}$ \\
\hline 2016 & 8,50 & Censo & DAP $\geq 15 \mathrm{~cm}$ & 2163 & 171 \\
2017 & 2 & 8 Parcelas $(50 \times 50 \mathrm{~m})$ & DAP $\geq 5 \mathrm{~cm}$ & 2309 & 186 \\
\hline
\end{tabular}

Fonte: Autores (2018).

\section{b) Dominância}

A área basal total para a área, representada pelo inventário a 100\% de intensidade realizado em 2016 foi de 18,54 $\mathrm{m}^{2}$.ha ${ }^{1}$, enquanto em 2017 registrou-se 23,20 m².ha ${ }^{1}$ (8 PP's - 50x50m). Foi possível observar um acréscimo em área basal na medição de 2017 pelo fato da inclusão dos indivíduos com DAP $\geq 5 \mathrm{~cm}$ no inventário, implicando com que se tenha um acúmulo maior em área basal.

Oliveira (1997), em área amostral em Belterra-PA, encontrou para dominância o valor de $18,9 \mathrm{~m}^{2} /$ ha para uma capoeira antiga de 50 anos. Já Melo (2004) avaliando 1hectare de floresta secundária no município de Marituba, região metropolitana de Belém-PA, encontrou 27,4m².ha1. Tais valores definidos nas amostragens realizadas pelos autores correspondem aos valores encontrados neste estudo quando consideramos os resultados obtidos pelas diferentes amostragens. Por outro lado, pode-se dizer também que a Capoeira do Black apresenta área basal equivalente às florestas primárias. A exemplo disso, Carvalho (1992) encontrou área basal de $30,7 \mathrm{~m}^{2}$.ha ${ }^{1}$ para uma floresta primária em Santarém, enquanto Vieira (1996) obteve 25,0m² ha $^{1}$ para um fragmento de floresta primária do Nordeste do Pará.

Deve-se considerar, no entanto, que os aspectos intrínsecos a este trabalho como o tamanho da área amostrada e o diâmetro de inclusão interferem no número de espécies encontradas, na dominância, densidade e em outros parâmetros.

Entre as espécies de maior abundância no fragmento, as de maior destaque tanto em densidade, como em dominância e, consequentemente, em valor de cobertura foram: Abarema jupunba, Tapirira guianensis e Nectandra cupidata. Juntas, essas espécies representam $21,5 \%$ da cobertura total da comunidade florestal da capoeira estudada (Tabela 6). 
Tabela 6 - Descritores fitossociológicos das vinte espécies de maior abundância no censo florestal (DAP $\geq 15 \mathrm{~cm})$. Ni ( $\mathrm{N}^{0}$ de indivíduos), DA e DR\% (Densidades absoluta e relativa), DoA e DoR (Dominâncias absoluta e relativa) e IVC\% (Índice de Valor de Cobertura relativo).

\begin{tabular}{|c|c|c|c|c|c|c|c|c|}
\hline & Espécies & $\begin{array}{l}\text { Nome } \\
\text { popular }\end{array}$ & $\mathrm{Ni}$ & DA & DR $\%$ & DoA & DoR $\%$ & IVC\% \\
\hline 1 & $\begin{array}{l}\text { Abarema jupunba } \\
\text { (Willd.) Britton \& Killip }\end{array}$ & Saboeiro & 172 & 20,24 & 7,69 & 0,18 & 8,22 & 7,94 \\
\hline 2 & $\begin{array}{l}\text { Tapirira guianensis } \\
\text { Aubl. }\end{array}$ & Tatapiririca & 155 & 18.24 & 6,93 & 0,14 & 6.22 & 7,00 \\
\hline 3 & $\begin{array}{l}\text { Nectandra cuspidata } \\
\text { Nees }\end{array}$ & $\begin{array}{l}\text { Louro- } \\
\text { preto }\end{array}$ & 117 & 13.76 & 5,23 & 0,08 & 3,49 & 6,56 \\
\hline 4 & Simarouba amara Aubl. & Marupá & 107 & 12,59 & 4,78 & 0,21 & 9,23 & 4,35 \\
\hline 5 & $\begin{array}{l}\text { Oenocarpus distichus } \\
\text { Mart. }\end{array}$ & Bacaba & 102 & 12,00 & 4,56 & 0,05 & 2,25 & 4,07 \\
\hline 6 & $\begin{array}{l}\text { Schefflera morototoni } \\
\text { (Aubl.) Maguire et al. }\end{array}$ & Morototó & 89 & 10,47 & 3,98 & 0,09 & 4,18 & 3,39 \\
\hline 7 & $\begin{array}{l}\text { Attalea maripa (Aubl.) } \\
\text { Mart. }\end{array}$ & Inajá & 72 & 8,47 & 3,22 & 0,07 & 3,24 & 3,23 \\
\hline 8 & $\begin{array}{l}\text { Pogonophora } \\
\text { schomburgkiana Miers } \\
\text { ex Benth. }\end{array}$ & Aracapuri & 70 & 8,24 & 3,13 & 0,06 & 2,66 & 3,21 \\
\hline 9 & $\begin{array}{l}\text { Lindackeria paraensis } \\
\text { Kuhlm. }\end{array}$ & $\begin{array}{l}\text { Farinha- } \\
\text { seca }\end{array}$ & 59 & 6,94 & 2,64 & 0,02 & 0,96 & 2,89 \\
\hline 10 & $\begin{array}{l}\text { Neea oppositifolia Ruiz } \\
\text { \& Pav. }\end{array}$ & João-mole & 58 & 6,82 & 2,59 & 0,02 & 1,05 & 2,54 \\
\hline 11 & Inga alba (Sw.) Willd. & $\begin{array}{l}\text { Ingá- } \\
\text { vermelho }\end{array}$ & 53 & 6,24 & 2,37 & 0,05 & 2,13 & 2,25 \\
\hline 12 & $\begin{array}{l}\text { Jacaranda copaia } \\
\text { (Aubl.) D.Don }\end{array}$ & Parapará & 50 & 5,88 & 2,23 & 0,06 & 2,85 & 2,25 \\
\hline 13 & Ormosia nobilis Tul. & $\begin{array}{l}\text { Tento-f1- } \\
\text { grande }\end{array}$ & 44 & 5,18 & 1,97 & 0,10 & 4,46 & 1,82 \\
\hline 14 & $\begin{array}{l}\text { Socratea exorrhiza } \\
\text { (Mart.) H. Wendl. }\end{array}$ & Paxiúba & 44 & 5,18 & 1,97 & 0,01 & 0,57 & 1,79 \\
\hline 15 & $\begin{array}{l}\text { Vochysia inundata } \\
\text { Ducke }\end{array}$ & Quaruba & 37 & 4,35 & 1.65 & 0,04 & 1.71 & 1,74 \\
\hline 16 & $\begin{array}{l}\text { Symphonia globulifera } \\
\text { L.f. }\end{array}$ & Anani & 35 & 4,12 & 1,56 & 0,02 & 1,00 & 1,68 \\
\hline 17 & $\begin{array}{l}\text { Cecropia distachya } \\
\text { Huber }\end{array}$ & $\begin{array}{l}\text { Embaúba- } \\
\text { distachya }\end{array}$ & 34 & 4,00 & 1.52 & 0,02 & 0,88 & 1,42 \\
\hline 18 & $\begin{array}{l}\text { Guatteria } \\
\text { schomburgkiana Mart. }\end{array}$ & $\begin{array}{l}\text { Envira- } \\
\text { preta }\end{array}$ & 33 & 3,88 & 1.47 & 0,02 & 1,09 & 1,41 \\
\hline 19 & Ocotea guianensis Aubl. & $\begin{array}{l}\text { Louro- } \\
\text { prata }\end{array}$ & 33 & 3,88 & 1,47 & 0,07 & 3,03 & 1,39 \\
\hline 20 & Byrsonima crispa A.Juss. & Muruci & 29 & 3,41 & 1,30 & 0,03 & 1,39 & 1,34 \\
\hline
\end{tabular}

Fonte: Autores (2018).

Quando se avalia a estrutura florística pela amostragem por parcelas, nota-se que há a reordenação das posições das espécies dada a inclusão de indivíduos com diâmetros menores, espécies características de sub-bosque. Na Tabela 7, são destacadas as espécies de acordo com os parâmetros de densidade, dominância, frequência e valor de importância. 
Tabela 7 - Parâmetros estruturais e fitossociológicos das 15 espécies com maior representatividade do índice de valor de importância (IVI\%) na amostragem de oito parcelas de 2017: Grupo ecológico (GE), Número de indivíduos (Ni), Densidade absoluta (DA), Área basal (G), Densidade relativa (DR), Frequência relativa (FR), Dominância relativa (DoR), e Índice de valor de importância (IVI).

\begin{tabular}{|c|c|c|c|c|c|c|c|c|}
\hline Espécie & GE & $\mathrm{Ni}$ & DA & $G\left(a^{2} / h a\right)$ & $\operatorname{DR}(\%)$ & $\mathrm{FR}(\%)$ & DoR $(\%)$ & IVI \\
\hline Aborema jugwmba (Willd) Britton \& Killip & Si & 123 & 61.5 & 2,359 & 5,33 & 7,13 & 10,17 & 22,62 \\
\hline Socratea exorrhiza (Mart) H.Wendl. & $\mathrm{Si}_{\mathbf{1}}$ & 142 & 71 & 0,764 & 6,15 & 8,23 & 3,29 & 17,67 \\
\hline Astrocazyum gynacanthow Mart & Si & 143 & 71,5 & 0,168 & 6.19 & 8,28 & 0,73 & 15,20 \\
\hline Heficostylis somenrosa (Poepp. \& Endl,) Rusby & Si & 85 & 42.5 & 0.567 & 3,68 & 4,31 & 2,44 & 10.43 \\
\hline Lindacheria paraensis Kuhln. & $\mathrm{Si}_{1}$ & 86 & 43 & 0,468 & 3.72 & 4,36 & 2,02 & 10.10 \\
\hline Symphonia globulifeno L.f. & St & 69 & 34,5 & 0,416 & 2,99 & 4,00 & 1,79 & 8,78 \\
\hline Thyrsodium spraceanum Besth. & St & 66 & 33 & 0,325 & 2,86 & 3,82 & 1,40 & 8.08 \\
\hline Ocorea aciphinlla (Nees \& Mart) Mez & St & 48 & 24 & 0.910 & 2,08 & 1,74 & 3.92 & 7.74 \\
\hline Euterpe olenacea Mart. & Si & 70 & 35 & 0,172 & 3.03 & 3.55 & 0,74 & 7,32 \\
\hline Neea oppositifolia Ruiz \& Pav. & $\mathrm{P}$ & 58 & 29 & 0,321 & 2,51 & 3,36 & 1.38 & 7,25 \\
\hline Simarouba amana Anbl. & $\mathrm{Si}$ & 31 & 15.5 & 0.757 & 1,34 & 1,80 & 3.26 & 6.40 \\
\hline Pourcurma grianemsis Aubl. & $\mathrm{Si}$ & 49 & 24,5 & 0,399 & 2,12 & 2,48 & 1,72 & 6.33 \\
\hline Tapirima gavianensis Aubl. & $\mathrm{P}$ & 29 & 14,5 & 0,838 & 1,26 & 1.05 & 3,61 & 5.92 \\
\hline Calliandna surinamensis Bentl. & Si & 51 & 25.5 & 0.095 & 2,21 & 295 & 0,41 & 5.57 \\
\hline Ormosia nobifis Tul var. nobilis & St & 22 & 11 & 0,715 & 0.95 & 1.27 & 3,08 & 5,31 \\
\hline Total 15 especies & & 1072 & 336 & 9.273 & 46,43 & 58,33 & 39.96 & 144.32 \\
\hline Demanis espécies (171) & & 1237 & 618,5 & 13,931 & 53,57 & 41,67 & 60.04 & 155,28 \\
\hline Total geral & & 2309 & 1154.5 & 23,204 & 100 & 100 & 100 & 300 \\
\hline
\end{tabular}

Fonte: Autores (2018).

Das espécies mais importantes encontradas na Capoeira do Black, Tapirira guianensis e Symphonia globulifera também se destacaram no trabalho de Vieira (1996), neste caso considerando uma capoeira antiga (40 anos). Já no trabalho de Oliveira (1997), para uma capoeira 50 anos, T. guianensis e L. paraensis estão entre as mais importantes.

\section{Distribuição nas Classes Diamétricas}

A Figura 8 apresenta a distribuição das árvores por classes diamétricas para a comunidade florestal da Capoeira do Black. No inventário a 100\% de intensidade, realizado em 2016, não houve mensuração para os indivíduos com diâmetro abaixo de $15 \mathrm{~cm}$. Em 2017, com a inclusão dos indivíduos com DAP $\geq 5 \mathrm{~cm}, 75,6 \%$ dos 2309 indivíduos foram representados na primeira classe. Foi possível observar também que a medida que aumentou o diâmetro das árvores, diminuiu a proporção dos indivíduos nas classes (padrão J' invertido, característico de florestas nativas). 
Figura 8 - Distribuição em classes de DAP do número de indivíduos por hectare nos levantamentos de 2016 (Censo) e 2017 (8 PP's - 50x50m) observados na Capoeira do Black, Belém, PA.

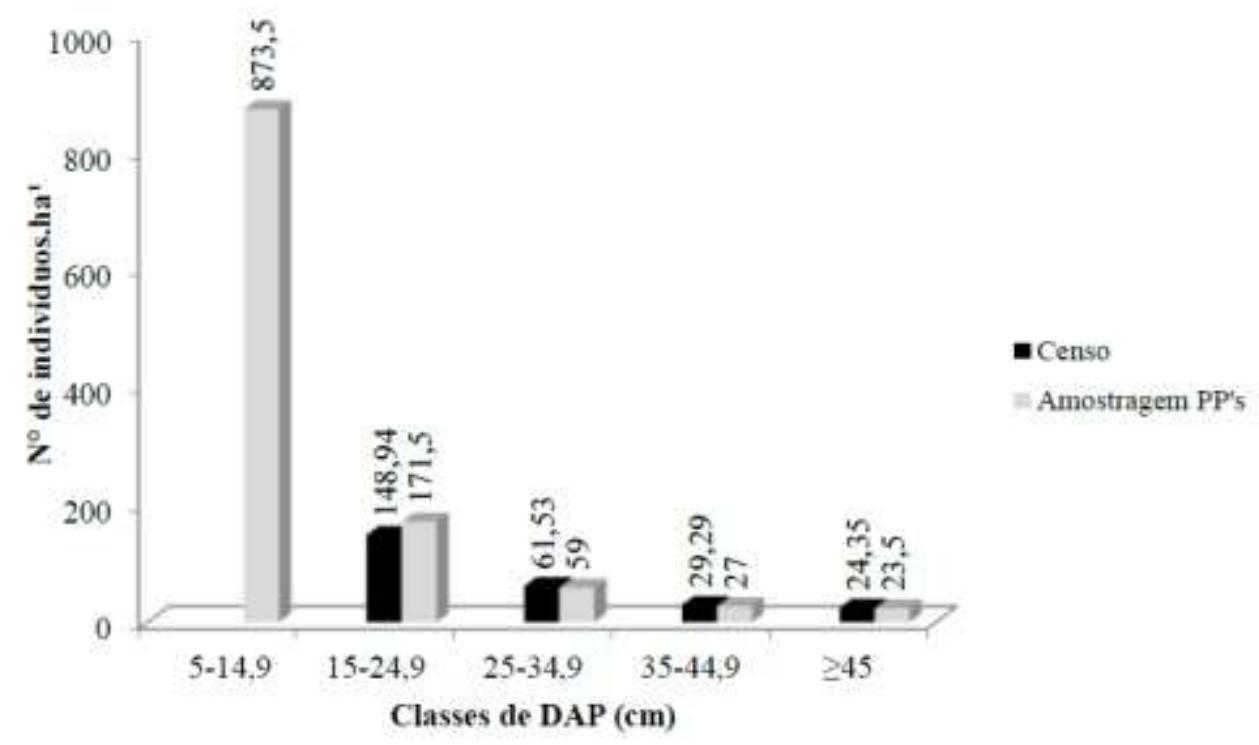

Fonte: Autores (2018).

De modo geral, todas as classes apresentaram redução do número de indivíduos ao longo do período analisado. Observando o número expressivo de indivíduos na primeira classe diamétrica, Vieira (1996) mostrou, em estudo realizado em uma floresta secundária de 40 anos, no Pará, que 76,7\% dos indivíduos estão distribuídos nesta classe. Isso mostra que a floresta do Black apresenta uma distribuição de indivíduos similar às demais florestas secundárias da região Nordeste do Pará.

O comportamento apresentado para a distribuição diamétrica para os dois levantamentos (Figura 8), segue o padrão de "J invertido", o que é um comportamento de crescimento esperado em florestas tropicais (HIGUCHI et al., 2013) . Essa distribuição garante que o processo dinâmico da floresta se perpetue, pois com o avanço dos processos sucessionais e a consequente morte de indivíduos, geralmente por senescência, dá lugar ao desenvolvimento de indivíduos jovens.

Na menor classe diamétrica $(5-14,9 \mathrm{~cm})$, para o levantamento de 2017, são encontrados tanto indivíduos jovens, regenerados a partir de espécies do dossel que passam por esse ambiente, quanto por espécies exclusivas de sub-bosque, como por exemplo muitos indivíduos de Tapirira guianensis, Abarema jupunba e Symphonia globulifera.

Entre as espécies distribuídas em todas as classes de diâmetro, nessa área destacaram- se as espécies que são classificadas segundo Finegan (1992), como heliófilas duráveis, ou seja, aquelas demandantes de luz que persistem na comunidade florestal por longos períodos, são elas: Ocotea guianensis, Ormosia nobilis, Simarouba amara, Tapirira guianensis, Schefflera morototoni, Ocotea aciphylla, Dipteryx odorata, Caryocar glabrum e Abarema jupunba.

\section{Relação da Composição florística do ambiente de borda e do interior do fragmento florestal}

Foram amostrados 1.200 indivíduos nas parcelas de borda e 1.109 indivíduos no interior do fragmento com DAP $\geq 5$ cm. Das 186 espécies amostradas entre as parcelas de borda e o interior do fragmento, 42 (22,6\%) ocorreram exclusivamente na área de borda, 37 (19,9\%) na área do interior e 107 (57,5\%) foram encontradas nos dois ambientes.

Analisando as dez espécies de maior valor de importância nos dois ambientes, destacam-se as espécies: Astrocaryum gynacanthum, Socratea exorrhiza, Abarema jupunba, Helicostylis tomentosa e Tapirira guianensis no ambiente de borda e 
Abarema jupunba, Socratea exorrhiza, Ocotea aciphylla, Astrocaryum gynacanthum e Thyrsodium spruceanum no interior, com todas essas espécies ocorrendo nos dois ambientes.

No total, foram amostradas 150 espécies, distribuídas em 46 famílias no ambiente de borda, sendo que, dentre estas, as mais representativas em número de espécies foram: Fabaceae (24), Myrtaceae (11), Annonaceae (9), Lecythidaceae (7), Arecaceae (6), Burseraceae (5), Lauraceae (5) e Sapincaceae (5). Foram ainda relevantes Sapotaceae e Urticaceae, ambas com 4 espécies cada, além de contribuem com 53,3\% do total de espécies inventariadas na borda (Figura 9). As outras 36 famílias apresentaram um total de 70 espécies $(46,7 \%)$, sendo representadas por três, dois ou somente um indivíduo.

Figura 9 - Relação das famílias mais representativas encontradas na borda florestal com os respectivos números de espécies observados na Capoeira do Black, Belém, PA.

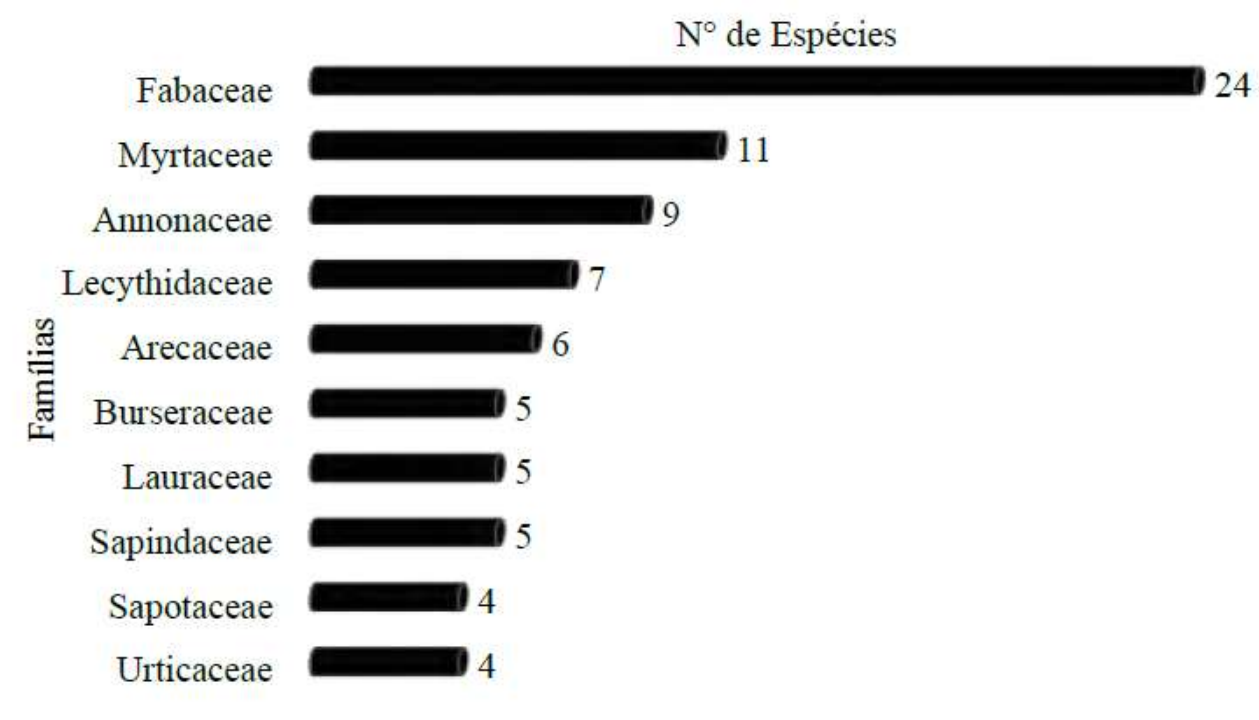

Fonte: Autores (2018).

No interior do fragmento, foram encontradas 144 espécies, distribuídas em 48 famílias botânicas. A maior riqueza é representada também pela família Fabaceae (23), seguida de Myrtaceae (8), Annonaceae (7), Lecythidaceae (7) e Sapindaceae (7). Outras famílias com destacadas foram Apocynaceae, Arecaceae e Myristicaceae, com 5 espécies cada, bem como Chrysobalanaceae e Elaeocarpaceae, ambas com 4 espécies. Estas contribuem com um total de 52,1\% do total de espécies amostradas no interior (Figura 10). As outras 38 famílias apresentam um total de 47,9\% das espécies presentes neste ambiente. 
Figura 10 - Relação das famílias mais representativas encontradas no interior florestal com os respectivos números de espécies observados na Capoeira do Black, Belém, PA.

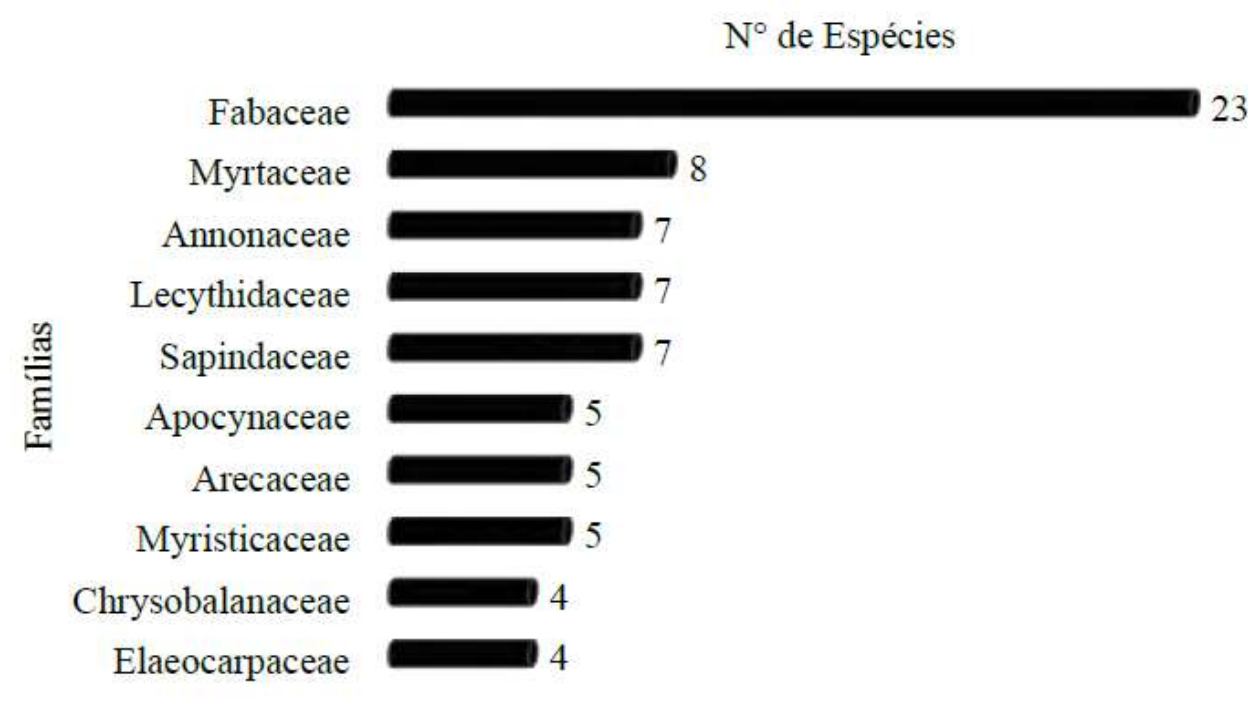

Fonte: Autores (2018).

Do total de 52 famílias analisadas, 42 (80,8\%) são comuns aos dois ambientes, ou seja, estão presentes tanto nas amostras de borda como nas amostras de interior; 4 famílias (7,8\%) só ocorrem na borda (Hypericaceae, Ochanaceae, Poaceae e Symplocaceae) e 6 famílias $(11,8 \%)$ só ocorrem no interior do fragmento (Celastraceae, Combretaceae, Linaceae, Menispermaceae, Metteniusaceae e Quiinaceae).

Como esperado para as florestas tropicais da Amazônia, um grupo restrito de famílias abriga uma grande concentração de espécies e, como mencionado anteriormente, a família Fabaceae destaca-se na maioria dos trabalhos que envolvem a ecologia de comunidades florestais na Amazônia. Para Souza e Lorenzi (2005), a família Fabaceae está incluída na maioria dos ecossistemas naturais brasileiros, e são bem perceptíveis e conhecidas aquelas que ocorrem nas bordas e em locais alterados.

\section{Estrutura, diversidade, similaridade e equabilidade entre os ambientes}

Na Tabela 8 estão descritos os valores de densidade por hectare, área basal por hectare e diâmetro médio dos indivíduos arbóreos por ambiente amostrado.

O ambiente de borda apresentou 91 indivíduos a mais em relação ao interior, isso significa dizer que densidade da borda é 3,95\% superior em relação ao interior do fragmento. O parâmetro de área basal foi um pouco superior no ambiente de interior em relação à borda.

Tabela 8 - Comparação do número de indivíduos por hectare e área basal por hectare entre a borda e o interior do fragmento florestal Capoeira do Black, Belém-PA.

\begin{tabular}{lll}
\hline Variável & Borda & Interior \\
\hline Número de indivíduos por hectare & 1.200 & 1.109 \\
Área basal por hectare $\left(\mathrm{m}^{2} . \mathrm{ha}^{1}\right)$ & 23,18 & 23,23 \\
\hline
\end{tabular}

Fonte: Autores (2018).

As dez espécies que apresentaram os maiores índices de valor de importância (IVI) em ordem decrescente na borda são: Astrocaryum gynacanthum, Socratea exorrhiza, Abarema jupunba, Helicostys tomentosa, Tapirira guianenis, 
Lindackeria paraensis, Euterpe oleraceae, Ocotea sp., Schefflera morototoni e Siparuna guianensis. Essas espécies juntas perfazem um total de $38,1 \%$ do índice de valor de importância, o que demonstra que uma composição diferente de espécies dominam a área da borda.

No interior do fragmento, as espécies Abarema jupunba, Socratea exorrhiza, Ocotea aciphylla, Astrocaryum gynacanthum, Thyrsodium spruceanum, Symphonia globulifera, Neea oppositifolia, Lindackeria paraensis, Ormosia nobilis e Neea floribunda são as dez mais importantes em relação ao índice de valor de importância (IVI), as quais somam 46,4\% do IVI total.

Whitmore (1990) destaca que em florestas tropicais com grande heterogeneidade florística, como no caso da Floresta amazônica, os fatores que contribuem para o aumento da densidade de poucas espécies estão relacionados diretamente aos distúrbios no ambiente, causados em sua maioria por atividades antrópicas.

Ainda na análise do IVI, a espécie Astrocaryum gynacanthum aparece em primeiro lugar na borda principalmente por ser uma das espécies mais abundantes neste ambiente, e por ser uma espécie heliófila com aptidão de crescimento sob a luz solar. No interior, essa mesma espécie aparece em quarto lugar, sendo esta posição adquirida pela dominância dessa espécie no ambiente (Figura 11).

Por sua vez, a espécie Abarema jupunba apresenta maior IVI no interior em decorrência da grande abundância de sua população, com elevados valores de densidade, frequência e dominância relativa. O grande número de indivíduos na borda do fragmento coloca esta mesma espécie em terceiro lugar no IVI no ambiente de borda (Figura 11).

Figura 11 - Relação das dez espécies com maior índice de valor de importância (IVI\%) encontradas na borda e no interior com suas respectivas posições observados na Capoeira do Black, Belém, PA, onde: $\mathrm{B}=$ borda; $\mathrm{I}$ = interior.

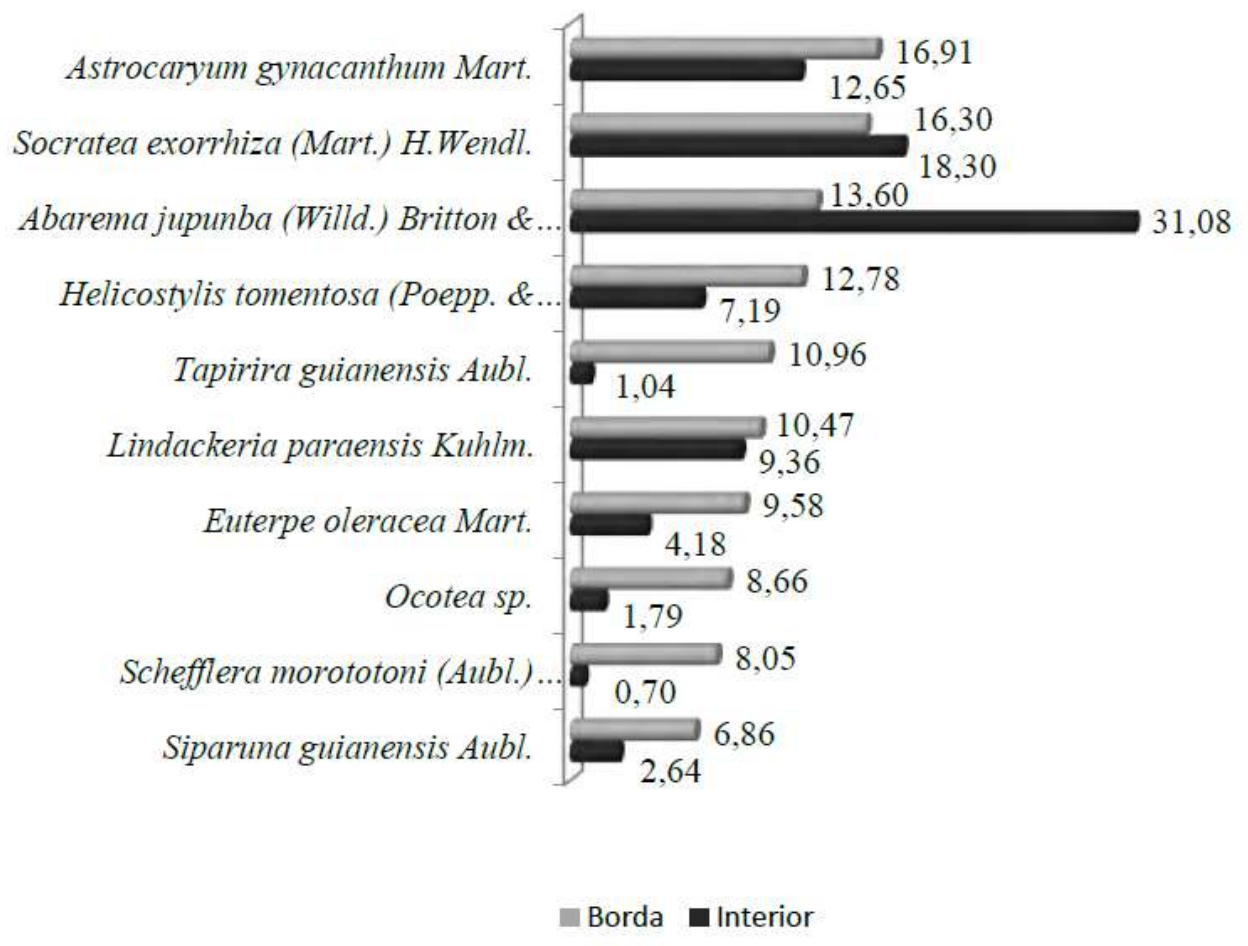

Fonte: Autores (2018). 
Observa-se que na distribuição diamétrica da comunidade estudada tanto na borda quanto no interior do fragmento há uma tendência a formação do "J" invertido (Figura 16). Esse padrão de distribuição, muito comum em florestas tropicais, indica a distribuição dos indivíduos em várias classes de diâmetro, com predominância nas iniciais.

Segundo Silva et al., (2009), em florestas secundárias a distribuição diamétrica com grande número de indivíduos jovens em relação aos indivíduos adultos denota que a comunidade está estável e crescendo gradualmente. Neste caso, como a maioria dos indivíduos concentraram-se na primeira classe (Figura 12), o que equivale a 75,7\% do total dos indivíduos amostrados na comunidade, pode-se presumir que a área da Capoeira do Black apresenta alta capacidade de regeneração das espécies.

Figura 12 - Distribuição dos indivíduos por classe de diâmetro $(\mathrm{cm})$ na borda e no interior do fragmento florestal Capoeira do Black, Belém, PA.

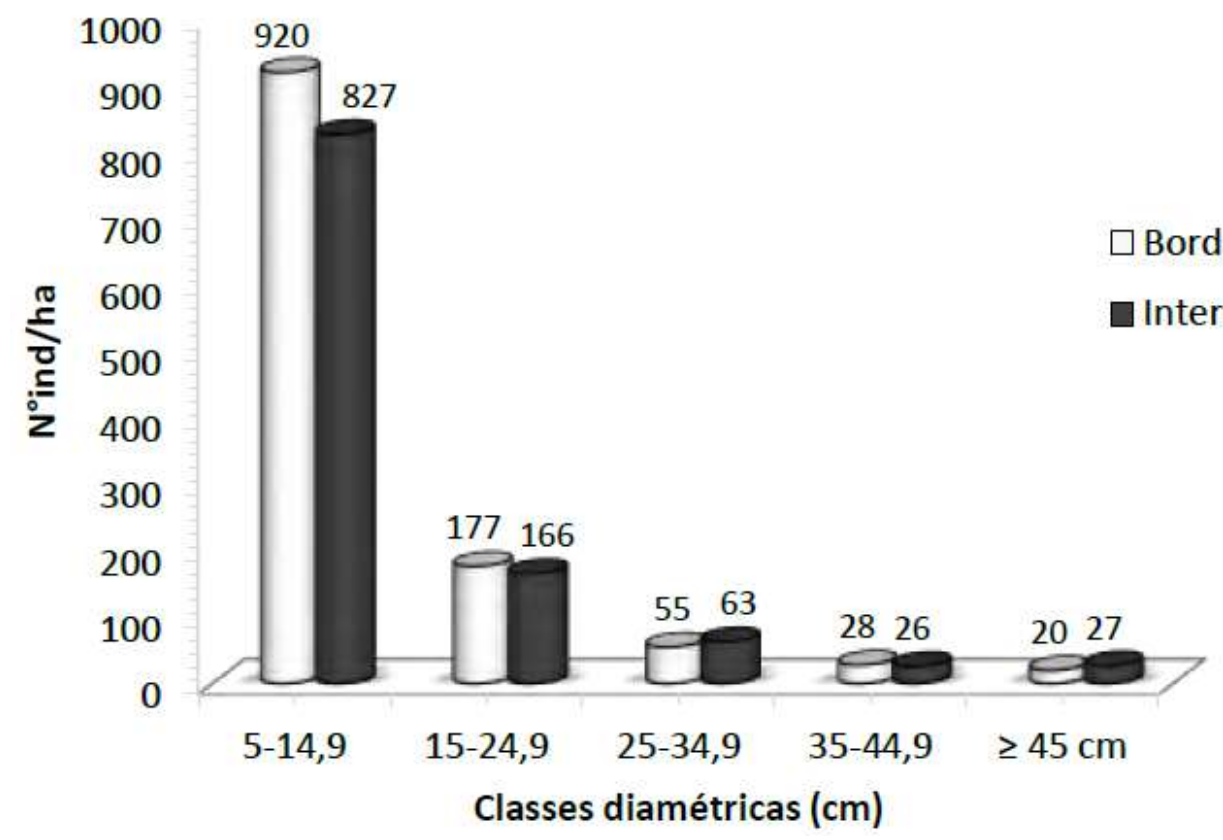

Fonte: Autores (2018).

Quando se avalia o comportamento diamétrico por ambiente, observa-se que 76,6\% dos indivíduos amostrados na borda encontram-se na primeira classe diamétrica. Da segunda classe até a quinta classe ocorre uma diminuição gradual do número de indivíduos.

Analisando a distribuição diamétrica no interior do fragmento, nota-se que $74,6 \%$ do total de indivíduos por hectare concentram-se na primeira classe de DAP, o que significa que a comunidade arbórea analisada é constituída, na sua maioria, de indivíduos de pouco porte elevado. Nas classes seguintes houve uma redução gradativa do número de indivíduos, estando presente apenas $25,4 \%$ das árvores amostradas.

O número reduzido de indivíduos nas classes mais elevadas de diâmetro pode estar relacionado à mortalidade ocasionada pelo efeito de borda, como já observado em outros fragmentos de florestas tropicais (Laurance et al., 2000; Moreira, 2009), ou um crescimento descontínuo das espécies arbóreas devido à ação de algum outro fator, inclusive antrópico. Em contrapartida, o aumento no número de árvores pequenas, especificamente na primeira classe, pode ter sido favorecido pelas perturbações ocorridas no passado por meio de intervenções na área (retirada de espécies arbóreas, queda natural de árvores, aumento da fragmentação...) facilitando o crescimento de espécies juvenis na comunidade. 
A diversidade de determinada área pode ser medida de forma simplificada por índices de diversidade, como o de Shannon (H’), que combinam o número de espécies que ocorrem na amostra, ou riqueza, com a distribuição de suas respectivas abundâncias, ou equabilidade (Moreira, 2009). O índice de diversidade de Shannon (H'), encontrado em florestas tropicais, varia de 3,83 a 5,86 (Faria, 2001), enquanto que a equabilidade de Pielou varia de 0,69 a 0,98.

O índice de Shannon encontrado para o ambiente de borda foi de 4,26 nats.ind ${ }^{-1}$ e a equabilidade de Pielou 0,85. Para o ambiente de interior do fragmento, a diversidade foi de 4,16 nats. ind ${ }^{-1}$ e uma equabilidade de 0,83 . A riqueza de espécies também foi superior na borda, mostrando que o padrão de distribuição dos indivíduos entre as espécies é maior no ambiente de borda (Tabela 9).

Tabela 9 - Índice de diversidade de Shannon (H'), Equabilidade de Pielou (J') e Riqueza (S) por ambiente (borda-interior) do fragmento florestal Capoeira do Black, Belém, PA.

\begin{tabular}{lccc}
\hline Ambiente & H' & J' & S \\
\hline Borda & 4,26 & 0,85 & 149 \\
Interior & 4,16 & 0,83 & 144 \\
Total & 4,35 & 0,83 & 186 \\
\hline
\end{tabular}

Fonte: Autores (2018).

Alguns fatores ambientais podem estar relacionados com essa distinção em diversidade entre a borda e o interior. Moreira (2009) leva em consideração que as bordas de fragmentos florestais são áreas de habitat mais expostas a perturbações externas e possuem, em geral, maior diversidade e maior produtividade biológica. Outros fatores ambientais que podem se associar a este ganho é o aumento da temperatura e luminosidade da área de borda em relação ao interior, o que cria condições favoráveis para a perpetuação de algumas espécies.

A diversidade geral apontada por intermédio do índice de Shannon para a área foi de 4,35 nats ind ${ }^{-1}$ e a Equabilidade de Pielou foi 0,83, o que indica que a Capoeira do Black é um fragmento florestal urbano com elevado índice de diversidade arbórea, uma vez que são valores muito próximos aos encontrados para florestas primárias da região.

Amaral et al. (2016) em seu estudo sobre as características ecológicas e estrutura da comunidade arbórea de uma área de endemismo em Belém encontrou um valor bem próximo de diversidade deste estudo, com $\mathrm{H}^{\prime}=4,27$ nats ind $^{-1}$ ).

Outros estudos também publicados por Amaral et al. (2009) contemplaram um "check list" da flora arbórea dos principais fragmentos florestais da região metropolitana de Belém, obtendo também valores de diversidade bem próximos ao deste estudo, cujos resultados foram: $\mathrm{H}^{\prime}=4,45$ nats ind $^{-1}$ (Bosque Rodrigues Alves), $\mathrm{H}^{\prime}=4,74$ (Parque do Gunma) e $\mathrm{H}^{\prime}=4,24$ (Reserva do Mocambo). Considerando estes dados pode-se dizer que todos esses fragmentos, de modo geral, apresentam alta diversidade florística, visto que, para as florestas tropicais, índices superiores a 3,83 são considerados altos.

Em um trabalho realizado por Melo (2004), onde estudando a florística e dinâmica de uma floresta secundária no município de Marituba-PA, encontrou valor semelhante ao que ocorre neste estudo, com índice de diversidade de Shannon $\left(\mathrm{H}^{\prime}=4,42\right.$ nats ind $\left.^{-1}\right)$ e o Índice de equabilidade de Pielou $\left(\mathrm{J}^{\prime}=0,83\right)$. De maneira análoga ao observado anteriormente, estes valores são também correspondentes aos encontrados no presente estudo. 
Quanto a similaridade florístico-estrutural para a amostragem, utilizando-se o índice de similaridade de Bray-Curtis (BC) foi de 58\% entre os dois ambientes do fragmento, o que significa dizer que em termos quantitativos há pouca correlação entre os ambientes de borda e interior quanto à composição florística e estrutura.

\section{Estágio Sucessional da Vegetação}

Os percentuais por grupo ecológico das espécies encontradas na borda e no interior do fragmento estão apresentados na Figura 13. Para as duas ocasiões houve predominância de espécies secundárias tardias em relação aos demais grupos.

Figura 13 - Distribuição das espécies por grupo ecológico nos diferentes ambientes do fragmento florestal urbano Capoeira do Black, Belém, PA, Brasil. P= Espécies pioneiras, $\mathrm{Si}$ = Secundária inicial, $\mathrm{St}=$ Secundária tardia, ND = Não determinada.
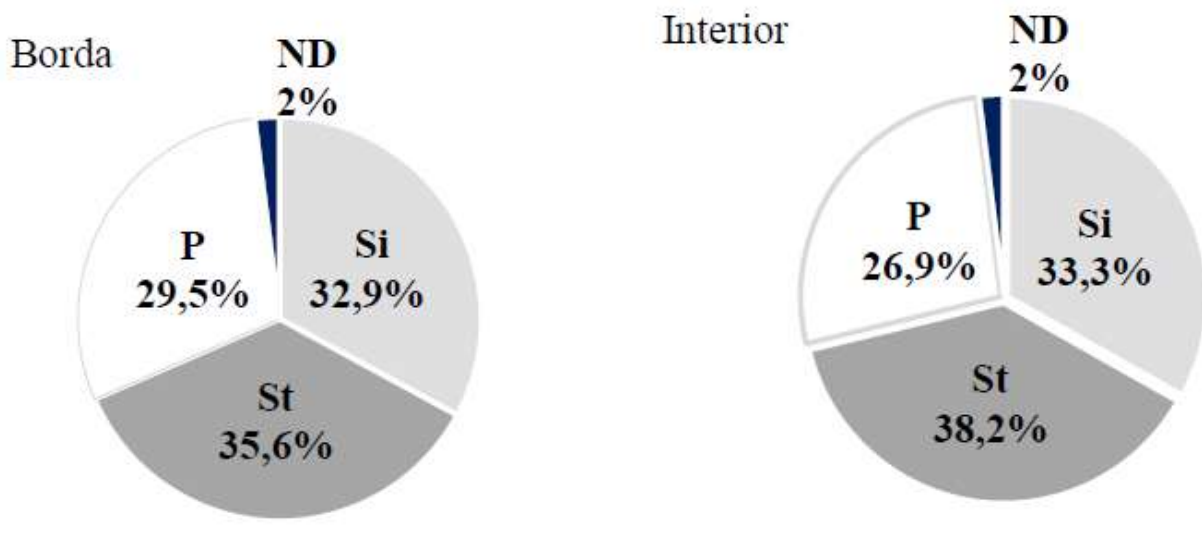

Fonte: Autores (2018).

O grupo ecológico que mais contribui para a composição da comunidade da borda foi o das secundárias tardias, com $35,6 \%$ do total das espécies amostradas, seguido das secundárias iniciais $(32,9 \%)$, pioneiras $(29,5 \%)$ e não determinadas $(2 \%)$ (Figura 13). Apesar das espécies secundárias tardias terem se destacado neste inventário como um todo, são as espécies associadas a sucessão inicial (pioneiras e secundárias iniciais) que apresentaram a maioria dos indivíduos encontrados na borda.

À medida que o nível de sombreamento na floresta vai se intensificando, as condições tendem a ficar propícias à ocorrência de espécies pertencentes ao grupo das secundárias tardias. Com isso, no interior do fragmento pode-se observar que também houve predominância do grupo das secundárias tardias, com 55 espécies $(38,2 \%)$, seguido pelas secundárias iniciais, com 48 espécies (33,3\%), pelas pioneiras, com 26,9\% e as não determinadas com 2\% (Figura 14). 
Figura 14 - Grupos ecológicos das espécies encontradas na borda e no interior do fragmento florestal com seus respectivos valores percentuais, onde: $\mathrm{Si}=$ secundárias iniciais $; \mathrm{St}=$ secundárias tardias; $\mathrm{P}=$ pioneiras e $\mathrm{ND}=$ não determinada.

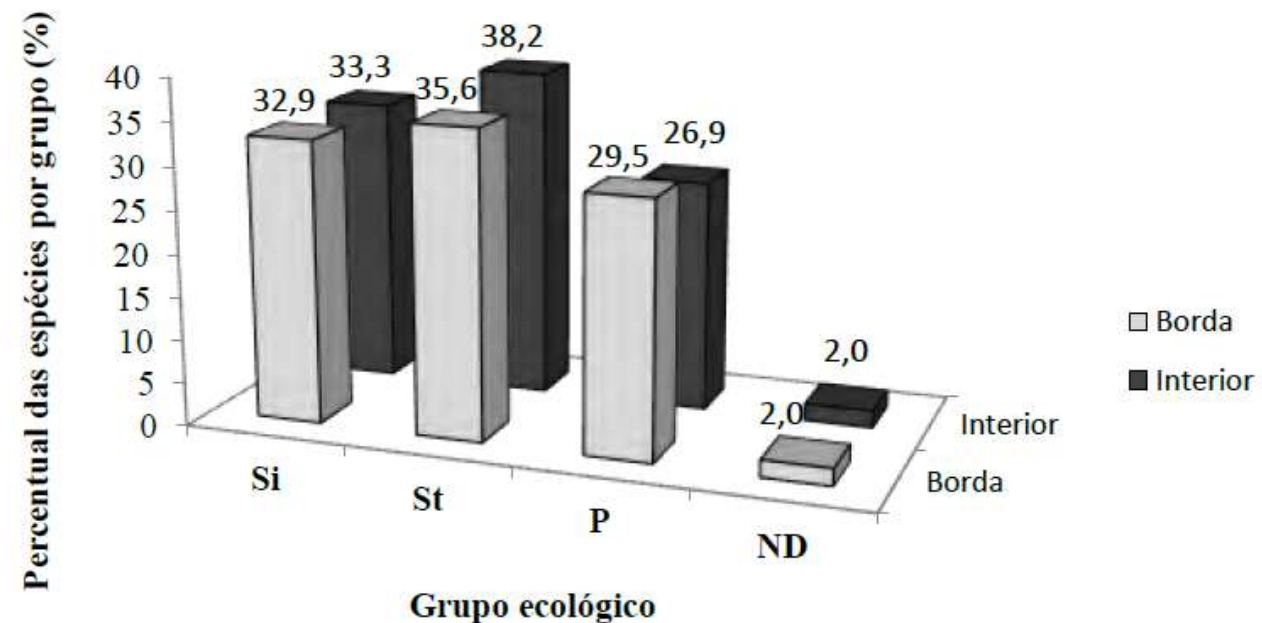

Fonte: Autores (2018).

\section{Grupo ecológico}

Com base na análise das dez espécies de maior IVI no ambiente da borda, observa-se a ocorrência de duas espécies no grupo das pioneiras (Tapirira guianensis e Schefflera morototoni), sete espécies no grupo das secundárias iniciais (Socratea exorrhiza, Abarema jupunba, Astrocaryum gynacanthum, Helicostilys tomentosa, Lindackeria paraensis, Euterpe oleraceae e Siparuna guianensis) e uma espécie no grupo das secundárias tardias (Ocotea Aubl).

Das dez famílias de maior IVI no interior do fragmento, destaca-se a presença de quatro famílias do grupo das secundárias tardias, que são: Ocotea aciphylla, Thyrsodium spruceanum, Symphonia globulifera e Ormosia nobilis.

Moreira (2009) menciona que alguns fatores como efeito de borda, decorrentes da fragmentação florestal proporcionam a formação de microclimas que favorecem o estabelecimento de espécies ditas oportunistas, representadas neste estudo pelas espécies Tapirira guianensis e Schefflera morototoni.

Budowski (1970) considera que o estágio sucesional de uma floresta é dado pelo grupo sucessional que apresentar maior proporção de indivíduos. Assim, os resultados apontam que a Capoeira do Black encontra-se em um estágio médio a avançado de desenvolvimento sucessional, podendo ser considerada como um remanescente de Floresta Ombrófila Densa secundária quanto à sua conservação.

Vale et al. (2009) apontam que quando uma floresta apresenta maiores proporções de espécies secundárias tardias e baixa proporção de espécies pioneiras, é um indicativo forte de uma área em avançado grau de maturidade e bom estágio de conservação.

Na Tabela 10 observa-se um resumo da distribuição percentual das espécies por grupo ecológico da Capoeira do Black e de outros fragmentos próximos localizados na região metropolitana de Belém, Pará. 
Tabela 10 - Distribuição percentual de espécies entre grupos sucessionais: Comparação entre a Capoeira do Black e fragmentos florestais adjacentes. Classificação baseada em Budowski (1965).

\begin{tabular}{ccccc}
\hline & \multicolumn{3}{c}{ Fragmentos Florestais } \\
\cline { 2 - 5 } Grupo Ecológico & $\begin{array}{c}\text { Bosque } \\
\text { Rodrigues } \\
\text { Alves }\end{array}$ & Mocambo & Combu & Capoeira do Black \\
\hline Pioneiras & 18.2 & 14.5 & 4.3 & 23.4 \\
Secundária inicial & 31.0 & 32.3 & 64.3 & 34.8 \\
Secundária tardia & 47.6 & 50.7 & 31.4 & 40.8 \\
Climácicas & 3.2 & 2.5 & 0 & 0.5 \\
N.D & - & - & - & 0.5 \\
\hline Total & 100 & 100 & 100 & 100 \\
\hline
\end{tabular}

Fonte: Amaral et al.(2009), modificado.

É possível notar que apesar de se tratar de fragmentos florestais geograficamente próximos, cada um apresenta a sua particularidade florística. Neles, quase metade das espécies é de sucessão secundária tardia, o que pode indicar que a Capoeira do Black é um fragmento florestal que apresenta características similares aos principais remanescentes florestais da região metropolitana de Belém.

\section{Dinâmica da Cobertura do Solo}

Os valores referentes à quantificação das classes associadas a Capoeira do Black, floresta secundária em estágio inicial de regeneração, floresta secundária em estágio médio de regeneração e solo exposto, podem ser observados na Figura 15.

O resultado dessa classificação mostra que a área ocupada por floresta secundária em estágio inicial de regeneração, representa 19,52\% da área na imagem de 1984; 10,12\% em 1996; 27,65\% em 2000; 13,88\% em 2005; 31,18\% em 2010; 14\% em 2015 e 4\% em 2018 (Figura 15). Da classe de floresta secundária em estágio médio de regeneração, observa-se uma evolução na ocupação desta classe no decorrer dos anos, com dois períodos de queda (anos 2000 e 2010), o que pode indicar possíveis intervenções na área. Tal classe apresenta: 61,29\% em 1984; 81,76\% em 1996; 52,35\% em 2000; 85,88\% em 2005; 60\% em 2010; 85,88\% em 2015 e 95,88\% de ocupação da área em 2018.

Tais valores indicam que de 1984 a 2018 houve uma redução em aproximadamente 20,49\% de ocupação da classe de floresta secundária em estágio inicial de regeneração e um acréscimo de 34,5\% na classe de floresta secundária em estágio médio de regeneração. 
Figura 15 - Distribuição em hectare das áreas representativas de cada classe de cobertura vegetal na Capoeira do Black entre os anos de 1984-2018.

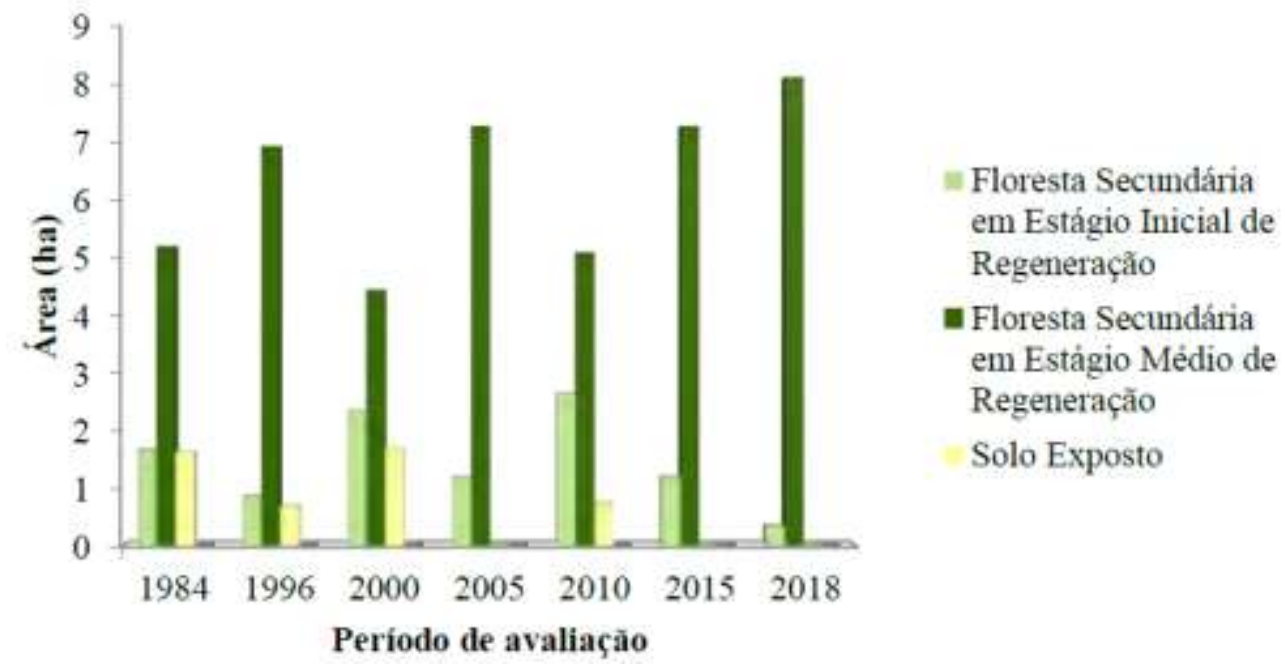

Fonte: Autores (2018).

Quanto à classe de solo exposto, nota-se valores pouco menos representativos de ocupação de área em relação as demais classes analisadas, com valores que variam de 19,06\% em 1984 a 8,70\% em 2010, e ausente nos anos 2015 e 2018.

A comparação dos dados obtidos com as imagens classificadas no período analisado, mostra que o acréscimo da área de floresta secundária em estágio médio de regeneração, em detrimento da redução das classes de floresta em estágio inicial e solo exposto. Tal constatação vem reforçar a hipótese de que a cobertura vegetal da Capoeira do Black, está tendendo à regeneração, apesar de ser uma área que sofre com intervenções antrópicas e naturais.

Esses resultados são condizentes com outros levantamentos realizados em áreas próximas à Capoeira do Black. A exemplo, Brasil Neto et al. (2014) utilizando produtos e técnicas de sensoriamento remoto, avaliaram a dinâmica do uso do solo no entorno do Parque Estadual do Utinga. Foi observado que a área dominada por ocupações urbanas cresceu continuamente entre 1984 a 2013, bem como uma quantidade elevada de áreas degradadas em volta dos núcleos urbanos e dentro da Área de Proteção Ambiental da Região Metropolitana de Belém - APA. Por outro lado, verificou-se também que a floresta que circunda o PEUt encontrase em processo de recuperação avançada.

Segundo Pará (2013), a vegetação secundária encontrada nas áreas do Parque Estadual do Utinga (PEUt) e no seu entorno, está em processo avançado de regeneração. Essa vegetação cede espaço para estratos arbóreos e dossel contínuo, elevando a área ocupada pela vegetação mais densa. Ao fazer um levantamento florístico da vegetação secundária no Parque Estadual do Utinga em 2011, Rocha et al. (2012) observaram uma homogeneidade de espécies e indivíduos presentes e oncluíram que a floresta apresenta características de ambiente em sucessão. Passado esses períodos de grandes antropismos, nos últimos anos de análise, a área de estudo vem se reestabelecendo e recuperando a sua estrutura florestal com uma gama de espécies e cumprindo o seu papel sucessional.

Nota-se que, em 2018, a classe com maior representatividade na área da Capoeira do Black é a Floresta Secundária em estágio médio de regeneração, ocupando uma área de 8,15 ha ou 95,8\%, ficando os demais 0,34ha ou 4\% da área ocupados pela classe de Floresta Secundária em estágio inicial de regeneração. Tais valores indicam a ocorrência de uma alta regeneração da floresta secundária ao longo desses 34 anos de avaliação.

Em um trabalho realizado por Torres e Lopes (2017), sobre a cobertura do solo do Parque Estadual do Utinga - PEUt, área esta adjacente a Capoeira do Black, também pode-se perceber uma dinâmica da vegetação classificada como secundária 
entre os anos de 2005 e 2015, cujo valores encontrados foram de 3,50ha e 5,51ha, respectivamente. Na Figura 16, estão ilustrados os mapas com os sete períodos distintos de avaliação da cobertura do solo na área de estudo.

Figura 16 - Série multitemporal de imagens de satélite conforme mapa de ocupação da cobertura do solo do fragmento florestal Capoeira do Black, referente aos anos de 1984, 1996, 2000, 2005, 2010, 2015 e 2018.

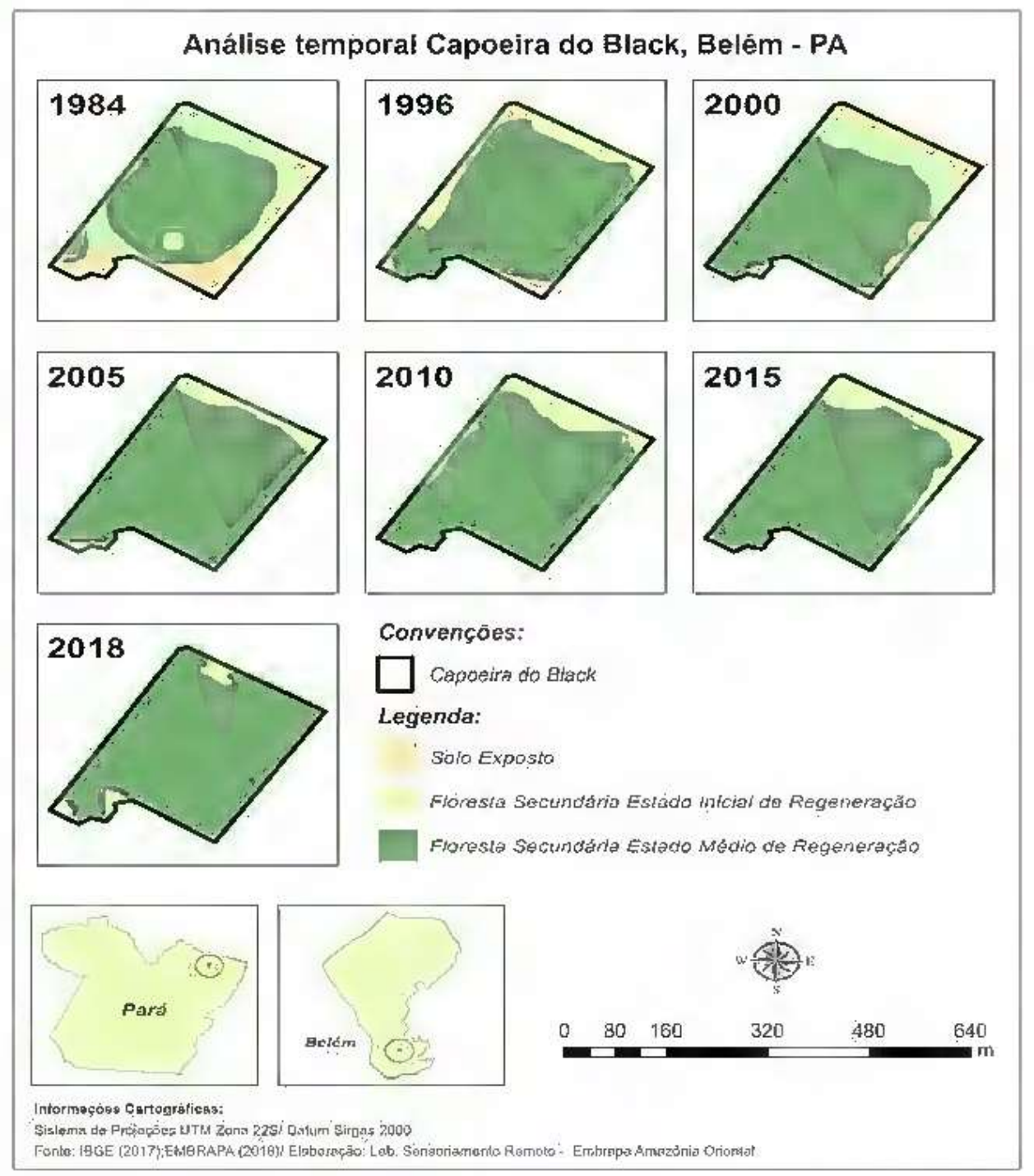

Fonte: Autores (2018).

A partir deles é possível notar uma evidente modificação na paisagem da Capoeira do Black ocorrida, principalmente, nas décadas de 80 e 90, quando se consolidava a construção da rodovia Murucutu (estrada da Ceasa), com registros de intervenções antrópicas por meio de invasões que promoveram o aumento da fragmentação florestal. Passado esses períodos de grandes antropismos, nos últimos anos de análise, a área de estudo vem se reestabelecendo e recuperando a sua estrutura florestal com uma gama de espécies e cumprindo o seu papel sucessional.

\section{Conclusões}

Os dados obtidos para os parâmetros de densidade e área basal do fragmento referentes a este trabalho, tanto a nível de censo como por amostragem das parcelas, indicou que os valores registrados são aproximados aos encontrados em 
remanescentes de florestas primárias e secundárias da região amazônica, com isso, confirmando-se a primeira hipótese deste trabalho. Pelas interações florístico-estruturais dos ambientes de borda e interior do fragmento, foi verificado, por meio dos índices de diversidade e riqueza, que o ambiente de borda apresenta valores um pouco superiores para esses parâmetros que os observados no interior do fragmento.

Os ambientes de borda e interior apresentaram alta similaridade florística, o que indica que mais da metade das espécies existentes na capoeira são encontradas nos dois ambientes, sendo exceção as espécies essencialmente heliófilas.

Os dados de campo e as análises de sensoriamento remoto indicaram que o fragmento encontra-se em estágio sucessional intermediário de sucessão ecológica, com a maioria das espécies referentes ao grupos das secundárias tardias para todas as ocasiões de amostragem.

Recomenda-se a conservação do fragmento Capoeira do Black, considerando-a importante e necessária para assegurar a conservação da ameaçada biodiversidade nele contida e nos demais fragmentos adjacentes da região metropolitana de Belém. Além do que, a área em questão serve como mostra de um patrimônio natural a ser preservado para garantir a manutenção da diversidade ainda existente.

\section{Referências}

Aguiar, A. P. D., Vieira, I. C. G., Assis, T. O., Dalla-Nora, E. L., Toledo, P. M., Santos-Junior, R. A. O., \& Ometto, J. P. H. (2016). Land use change emission scenarios: Anticipating a forest transition process in the Brazilian Amazon. Global Change Biology, 22, 1821-1840.

Alves Júnior, F. T., Brandão, C. F. L. S., Rocha, K. D., Silva, J. T. Da, Marangon, L. C., \& Ferreira, R. L. C. (2007). Estrutura diamétrica e hipsométrica do componente arbóreo de um fragmento de Mata Atlântica, Recife-PE. Cerne, Lavras, 13(1), 83-95.

Alvey, A. A. (2006). Promoting and preserving biodiversity in the urban forest. Urban Forestry \& Urban Greening, Amsterdam, 5, $195-201$.

Amaral, D. D., Vieira, I. C. G., \& Almeida, S. S. (2016). Características ecológicas e estrutura da comunidade arbórea de um remanescente florestal na Área de Endemismo Belém. Revista Brasileira de Biociências, 14(4).

Amaral, D. D., Vieira, I. C. G., Almeida, S. S., Salomão, R. P., Silva, A. S. L., \& Jardim, M. A. G. (2009). Checklist da flora arbórea de remanescentes florestais da região metropolitana de Belém e valor histórico dos fragmentos, Pará, Brasil. Boletim do Museu Paraense Emílio Goeldi. Ciências Naturais. 4(3), 231-289.

Badiru, A. I. (2005). Método para a classificação tipológica da floresta urbana visando o planejamento e a gestão das cidades. In: Anais Simpósio Brasileiro de Sensoriamento Remoto, 12., Goiânia, 16-21 abril. São José dos Campos: INPE, 2005, 1427- 1433.

Bastos, T. X., Gomes, J. I., \& Rodrigues, S. T. (2007). Aspectos bioclimáticos de uma área de conservação florestal urbana na Amazônia Brasileira. In: Gomes, J. I., Martins, M. B., Martins-Da-Silva, Almeida, S.S. Mocambo: diversidade e dinâmica biológica da Área de Pesquisa Ecológica do Guamá (Apeg). Museu Paraense Emilio Goeldi/ Embrapa Amazônia Oriental. Belém, p. 283-292.

Begon, M., Townsend, C., \& Harper, J. (2006). Ecology: from individual to ecosystems. Quarta. Blackwell.

Belemtur. (2018). Coordenadoria Municipal de Turismo. https://www.belem.pa.gov/belemtur/site.

Benedetti, A. C. P. (2010). Modelagem dinâmica para simulação de mudanças na cobertura florestal das Serras do Sudeste e Campanha Meridional do Rio Grande do Sul. 166 f. Tese (Doutorado em Engenharia Florestal) - Universidade Federal de Santa Maria, Santa Maria.

Brasil Neto, A. B., Paumgartten, A. E. A., Braga, A. N., Maciel, M. N. M., \& Silva, P. T. E. (2014). Dinâmica da cobertura vegetal e uso do solo no entorno do parque estadual do Utinga (PEUt), Belém-PA. Enciclopédia Biosfera, 10, 2120-2128.

Bray, J. R., \& Curtis, J. T. (1957). An ordination of the upland forest communities of southern Wisconsin. Ecological Monographs, $27,325-349$.

Briassoulis, H. (2000). Analysis of land use change: theoretical and modeling approaches. Regional Research Institute, West Virginia University.

Budowski, G. (1965). Distribution of tropical American rain forest species in the light of successional processes. Turrialba, 15(1), 440-442.

Budowski, G. (1966) Los bosques de los trópicos húmedos de América. Turrialba, 16(3), 278-285.

Budowski, G. (1970). The distinction between old secondary and climax species in tropical central american lowland rainforest. Tropical Ecology, Varanasi, 11, p.44-48.

Cain, S. A., Castro, G. M. O., Pires, J. M., \& Silva, N. T. S. (1956). Application of some phytosociologial techniques to Brasilian rain forest, American Journal of Botany. 43(10), 911-941. https://doi.org/10.1002/j.1537-2197.1956.tb11184.x

Calegari, L., Martins, S. , Gleriani, J. M., Silva, E., \& Busato, L. C. (2010). Análise da dinâmica de fragmentos florestais no município de Carandaí, MG, para fins de restauração florestal. Revista Árvore, 34(5), 871-880. https://dx.doi.org/10.1590/S0100-67622010000500012. 
Callegaro, R. M. (2012). Variações florísticas e estruturais de um remanescente de Floresta Ombrófila Mista Montana em Nova Prata - RS. Dissertação (Mestrado em Engenharia Florestal). Santa Maria, RS: Universidade Federal de Santa Maria, Centro de Ciências Rurais, Programa de Pós-Graduação em Engenharia Florestal. 96p.

Carim, S., Schwartz, G. \& Silva, M. F. F. (2007). Riqueza de espécies, estrutura e composição florística de uma floresta secundária de 40 anos no leste da Amazônia. Acta Botanica Brasilica, 21(2), 293-308. https://dx.doi.org/10.1590/S0102-33062007000200005

Carvalho Junior, O. A., Guimar, R. F., Carvalho, A. F., Gomes, R. A. T., Melo, \& A. F., Silva, A. (2005). Processamento e análise de imagens multitemporais para o perímetro de irrigação de Gorutuba (MG). In: Anais XII Simpósio Brasileiro De Sensoriamento Remoto. Goiânia, 2005. INPE, 473-480. http://marte.sid.inpe.br/col/ltid.inpe.br/sbsr/2004/12.06.13.32/doc/473.pdf

Carvalho, J. O. De. (1992). Structure and dynamics of a logged over Brazilian Amazonian rain forest. Oxford. 215Thesis (PhD.) - University of Oxford.

Chazdon, R. (2012). Regeneração de florestas tropicais. Boletim do Museu Paraense Emílio Goeldi. Ciências Naturais, Belém, 7(3), $195-218$.

Cielo Filho, R., \& Santin, D. A. (2002). Estudo florístico e fitossociológico de um fragmento florestal urbano: Bosque dos Alemães, Campinas, SRevista Brasileira de Botânica, São Paulo, 25(3), 291-301.

CIENTEC. (2006). Consultoria e Desenvolvimento de Sistemas. Mata nativa 2: Sistema para análise fitossociológica e elaboração de inventários e planos de manejo de florestas nativas - manual do usuário. Viçosa: Cientec. 295 p.

Coelho, R. F. R, Miranda, I. S., \& Mitja, D. (2013). Conservação das florestas do Projeto de Assentamento Benfica, Sudeste da Amazônia. Ciência Florestal, 23, n.1, 1-17.

Colwell, R. K., \& Coddington, J. A. (1994). Estimating terrestrial biodiversity through estrapolation. Philos Trans R Soc Lond B Biol Sci., 345(1311):101-18. 10.1098/rstb.1994.0091.

Cottan, G, \& Curtis, J. T. (1956). The use of distance measures in phytosociological sampling. Ecology, 37(3), 451-460.

Dislich, R., Cersósimo, L., \& Mantovani, W. (2001). Análise da estrutura de fragmentos florestais no Planalto Paulistano-SRevista Brasileira de Botânica, 24(3), 321-332.

Ducke, A., \& Black, G. A. (1954). Notas sobre a fitogeografia da Amazônia Brasileira. Belém: lnstituto Agronômico do Norte, 62 Boletim Técnico n. 29.

Egler, W. (1960). Contribuições ao conhecimento dos campos da Amazônia: os campos do Ariramba. Boletim do Museu Paraense Emilio Goeldi. n. 4, 40 jun. (Série Botânica).

Embrapa-Empresa Brasileira de Pesquisa Agropecuária. (2005). Embrapa comemora aniversário e inaugura trilha ecológica. 29/04/2005. URL: https://www.embrapa.br/busca- de-noticias/-/noticia/17988523/embrapa-comemora-aniversario-e-inaugura-trilha-ecologica.

Embrapa Amazônia Oriental. (1997). Zoneamento da área física da sede do CPATU. Relatório Técnico. Belém: Embrapa Amazônia Oriental. 21 p.

Fao. (2010). Global Forest Resources Assessment. Rome, Italy: Food and Agriculture Organization of the United Nations.

Faria, (2001). Composição florística e estrutura de vegetação colonizadora de clareiras em floresta atlântica sob manejo sustentável. Dissertação (Mestrado em Ciência Florestal), Universidade Federal de Viçosa, Viçosa.

Fearnside, (2006). Desmatamento na Amazônia: dinâmica, impactos e controle. Acta Amazônica, Manaus: AM, 36 (3), $395-400$.

Felfili, J. M., \& Rezende, R. (2003). Conceitos e métodos em fitossociologia. Brasília: Universidade de Brasília. 68 p.

Ferreira, L. , Parolin, P., Muñoz, S. H., \& Chaves, (2012). O efeito da fragmentação e isolamento florestal das áreas verdes da Região Metropolitana de Belém. Instituto Anchietano de Pesquisas, São Leopoldo-RS. Pesquisas Botânicas. (63), 357-367.

Finegan, B. (1992). Bases ecologicas de la silvicultura y la agroforesteria Turrialba. Costa Rica: CATIE. 153p.

Fiszon, J. T., Marchioro, N. X, Britez, R., Cabral, D. C., \& Camely, N. (2003). Causas da fragmentação: causas antrópicas. In: RAMBALDI, D. M., OLIVEIRA, D. A. S. (orgs.). Fragmentação de ecossistemas: causas, efeitos sobre a biodiversidade e recomendações de políticas públicas. Brasília: MMA/SBF, 510 https://www.researchgate.net/publication/326845865_Causas_antropicas_da_fragmentacao/citations\#fullTextFileContent

Flora Do Brasil. (2016). Jardim Botânico do Rio de Janeiro. http://www.floradobrasil.jbrj.gobr/.

Gomes, J. I., Martins, M. B., Martins-Da-Silva, R. C., \& Almeida, S.S. (2007). Mocambo: diversidade e dinâmica biológica da Área de Pesquisa Ecológica do Guamá (APEG). Museu Paraense Emilio Goeldi/ Embrapa Amazônia Oriental. Belém, 454 p.

Gradwohl, J., \& Greenberg, R. (1991). Small forest reserves: making the best of a bad situation. Climatic change, 19, $235-256$.

Grey, G. W., \& Deneke, F. J. (1992). Urban forestry. (2nd ed.). Malabar, FL: Krieger Publishing Company.

Higuchi, P., Silva, A. C., Almeida, J. A., Bortoluzzi, R. L. C., Mantovani, A., Ferreira, T. S., Souza, S. T., Gomes, J. P., \& Silva, K. M. (2013). Florıśtica e estrutura do componente arbóreo e análise ambiental de um fragmento de floresta ombrófila mista altomontana no município de Painel, SC. Ciência Florestal. 23 , n. 1, 153-164.

Ideflorbio-Pa. Portal de notícias. (2018). Parque estadual do Utinga - PEUt. http://ideflorbio.pa.gobr. 
Ilkiu-Borges, F. De S., Gomes, J. I., \& Rodrigues, S. T. (2007). Potencial de uso das florestas secundárias da Amazônia representado pela "Capoeira do Black". Anais: $58^{\circ}$ Congresso Nacional de Botânica. São Paulo. https://www.embrapa.br/busca-de-publicacoes/-/publicacao/409292/potencial-de-uso-das-floressecundarias-da-amazonia-representado-pela-capoeira-do-black

Instituto Brasileiro De Geografia E Estatística - IBGE. (2012). Manual técnico da vegetação brasileira: sistema fitogeográfico, inventário das formações florestais e campestres, técnicas e manejo de coleções botânicas, procedimentos para mapeamentos. Rio de janeiro: IBGE- Diretoria de Geociências. 271(Manuais Técnicos de Geociências, 1).

Instituto De Pesquisa E Experimentação Agropecuária Do Norte (IPEAN). (1966). Área de Pesquisas Ecológicas do Guamá: um programa integrado de colaboração científico-educacional na Amazônia. Coletânea de atos deliberativos, cartas circulares, programas de pesquisas, mapas, etc. Belém: IPEAN. s/https://www.embrapa.br/busca-de-publicacoes/-/publicacao/375567/area-de-pesquisa-ecologicas-do-guama-um-programa-integrado-de-colaboracaocientifico-educacional-na-amazonia.

Jakovac, C. C., Bongers, F., Kuyper, T. W., Mesquita, R. C. G., \& Peña-Claros, M. (2016). Land use as a filter for species composition in Amazonian secondary forests. Journal of Vegetation Science, 27, 1104-1116.

Júnior, J. S. B., \& Almeida, A. S. de. (2010). Análise multitemporal com a utilização da técnica de sensoriamento remoto e geoprocessamento no município de Bonito - Pará. Anais Simposio Brasileiro De Ciências Geodésicas ETecnologias Da Geoinformação, 3, Recife, 2010.01 - 07.

Laurance, W. F., Delamônica, P., Laurance, S. G., Vasconcelos, H. L, \& Lovejoy T. E. Rainforest fragmentation kills big trees. Nature. 2000 Apr 20,404(6780):836. doi: 10.1038/35009032. PMID: 10786782 .

Leão, N., Alencar, C., \& Veríssimo, A. (2007). Belém Sustentável: 1-140. Imazon, Belém. https://imazon.org.br/PDFimazon/Portugues/livros/belem-sustentavel2007.pdf

Legendre, P., Legendre, L. Numerical Ecology. (3a ed.), USA: Elsevier, 2012. 990p.

Lima, R. B. A., Silva, J. A. A., Maragon, L. C., Ferreira, R. L. C., \& Silva, R. K. S. Sucessão ecológica de um trecho de Floresta Ombrófila Densa de Terras Baixas, Caruari, Amazonas. Pesquisa Florestal Brasileira. 31(67), 161-172. 2011.

Machado, R. R. B., Pereira, E. C. G., \& Andrade, L. H. C. (2010). Evolução temporal (2000-2006) da cobertura vegetal na zona urbana do município de Teresina - Piauí - Brasil. REVSBAU. Piracicaba, S5(3), 97-112.

Magalhães, L. M. S. (2006). Arborização e florestas urbanas: terminologia adotada para a cobertura arbórea das cidades Brasileiras. Série Técnica Floresta e Ambiente, Seropédica, 1, 23-26.

Magurran, A. E. (2009). Measuring biological diversity. Oxford: Blackwell Science, 2004. 215MARRIS, E. Ragamuffin Earth. Nature. 460 , $450-453$.

Martins, S., Silva, N. R. S., Souza, A. L. \& Meira Neto, J. A. A. (2003). Distribuição de espécies arbóreas em um gradiente topográfico de Floresta Estacional Semidecidual em Viçosa, MG. Scientia Forestalis. 64, 172-181.

Matteuci, S. D., \& Colma, A. (1982). Metodología para el estudio de la vegetación. Washington: Secretaria General de la Organización de los Estados Americanos. 168 p.

Melo, M. S. (2004). Florística, fitossociologia e dinâmica de duas florestas secundárias antigas com histórias de uso diferentes no nordeste do Pará-Brasil. Piracicaba-SP: Esalq/USP.

Metzger, J. W. (1998). Changements de la struture du paysage et richese spécifique dês fragments forestiers dans lê sud-est du Brésil. Comptes rendus de l'Académie des Sciences Paris. Paris, 321, 319-333.

Miller, R. W. (1997). Urban forestry: planning and managing urban greenspaces. (2nd ed.). Upper Saddle River, N.J: Prentice-Hall, Inc.

Miller, T., \& Spoolman, S. (2009). Essentials of ecology. Quinta. Brooks/cole.

Moreira, E. (1966). Belém e sua expressão geográfica. Belém: Imprensa Universitária.

Moreira, L. N. (2009). Fitossociologia em ambiente de borda de fragmento de floresta estacional semidecidual. Dissertação (Mestrado em Produção Vegetal), UniversidadeFederal do Espírito Santo, Alegre.

Mueller-Dombois, D., \& Ellenberg, H. (1974). Aims and methods of vegetation ecology. Wiley.

Museu Paraense Emilio Goeldi. (2018). Portal de notícias. https://www.museu-goeldi.br.

Nilon, C. H. (2011). Urban biodiversity and the importance of management and conservation. Landscape and Ecological Engineering, Tokyo, 7, 45-52.

Nowak, J. N., Noble, M. H., Sisinni, S. M., \& Dwyer, J. F. (2001). Peole \& trees: assessing the US urban forest resourse. Journal of Forestry. 99(3), 37-42.

Oliveira, L. C de. (1997). Dinâmica de crescimento e regeneração natural de uma floresta secundária no Estado do Pará - Belém. 136p - Dissertação (Mestrado) - Universidade Federal do Pará.

Oliveira-Filho, A. T. (1994). Estudos ecológicos da vegetação como subsídio para programas de revegetação com espécies nativas: uma proposta metodológica. Cerne, Lavras, 1(1), 64- 72.

Pará. Secretaria Estadual do Meio Ambiente. (2013). Revisão do Plano de Manejo do Parque Estadual do Utinga./ Secretaria de Estado de Meio Ambiente. Belém: SEMA: Belém: IMAZON.

Péllico Netto, S., \& Brena, D. A. (1997). Inventário florestal. Ed. S. Péllico Netto, D.A. Brena,. Curitiba. 316 páginas 
Pielou, E. C. (1966). The measurement of diversity in different types of biological collections. Journal Theoret. Biol., 13, 131-144.

Pillar, D. (1998). Sampling sufficiency in ecological surveys. Abstracta Botanica, 22, 37- 48.

Portal Diário De Notícias Do Pará. (2018). Bosque Rodrigues Alves. http://www.diarioonline.com.br/noticia-163170-bosque-rodrigues-alves-completa-128anos.

Puig, H. (2008). A floresta tropical úmida. São Paulo: Editora UNESP Imprensa Oficial do Estado de São Paulo, França: Institut de Rechérche pour le Développement. $496 \mathrm{p}$.

Ribeiro, M. C., Metzger, J. P., Martensen, A. C., Ponzoni, F. J., \& Hirota, M. M.(2009). The Brazilian Atlantic Forest: How much is left, and how is the remaining forest distributed? Implications for conservation, Biological Conservation, 142(6), 1141-1153. https://doi.org/10.1016/j.biocon.2009.02.021.

Rocha, N. C., Alvez, M. N. C. B., Moura, Q. L., Souza, A. S., \& Rocha, M. M. B. (2012). Levantamento florístico de floresta tropical secundária na área do Parque Ambiental do Utinga, Belém-PA. Enciclopédia Biosfera, Centro Científico Conhecer - Goiânia, 8(14), 1299-1309.

Salomão, R. P., Vieira, I. C. G., Brienza Júnior, S., Amara, D. D., \& Santana, A. C. (2012). Sistema Capoeira Classe: uma proposta de sistema de classificação de estágios sucessionais de florestas secundárias para o estado do Pará. Boletim do Museu Paraense Emílio Goeldi. Ciências Naturais. 7(3), $297-317$.

Santin, D. A. (1999). A vegetação remanescente no município de Campinas (SP): mapeamento, caracterização fisionômica e florística, visando a conservação 502Tese (Doutorado em Ciências Biológicas) - Universidade Estadual de Campinas, Campinas.

Saunders, D. A., Hobbs, R. J., \& Margules, C. R. (1991). Biological consequences of ecosystem fragmentation: a rewiew. Conservation Biology, Boston, 5(1), 12-32, Mar.

Schneider, R., \& Finger, C. A. G. (2000). Manejo sustentado de florestas inequiâneas heterogêneas. Santa Maria: UFMS.

Schwartz, G. (2007). Manejo sustentável de florestas secundárias: espécies potenciais no nordeste do Pará, Brasil. Amazônia: Ciência e Desenvolvimento, 3, $125-147$.

Semas. (2015). Instrução Normativa 08, de 28/10/2015, http://www.semas.pa.gobr/2015/11/03/instrucao-normativa-no-08-de-28- de-outubro-de-2015/.

Shannon, C. E., \& Weaver, W. (1949). The mathematical theory of communication. Urbana: University of Illinois Press, 117p.

Silva, A. C., Berg, E. D., Higuchi, H., Oliveira-Filho, A. T., Marques, J. J. G. S. M., Appolinario, , Pifano, D. S., Ogusuku, L. M., \& Nunes, M. H. (2009). Floriśtica e estrutura da comunidade arbórea em fragmentos de floresta aluvial em São Sebastião da Bela Vista, Minas Gerais, Brasil. Revista Brasileira Botânica, 32(2), 283-297.

Souza, A. L. De, \& Soares, C. B. (2013). Florestas Nativas. Editora UFV, 322

Souza, C., \& Lorenzi, H. (2005). Botânica sistemática: guia ilustrado para identificação das famílias de Angiospermas da flora brasileira, baseado em APG II. Nova Odessa, SP.

Tabarelli, M., Silva, J. M. C., \& Gascon, C. (2004). Forest fragmentation, synergisms and the impoverishment of neotropical forests. Biodiversity and Conservation, Dordrecht, 13(7), 1419-1425.

Torres, J. B., \& Lopes, R. B. (2017). Análise multitemporal do uso e ocupação do solo ao entorno da área de unidade de conservação, Utinga - PA, anos 2005 2015. https://www.2015.7324-7328. 10.20396/sbgfa.v1i2017.2288.

Vale, I., Costa, L. G. S., \& Miranda, I. S. (2014). Espécies indicadas para a recomposição da floresta ciliar da sub-bacia do Rio Peixe-Boi, Pará. Ciência Florestal. 24, n. 3, 573-582.

Vale, S., Schiavini, I., Lopes, S. F., Dias-Neto, O. C., Oliveira, A. P., \& Gusson, A. E. (2009). Composição florística e estrutura do componente arbóreo de um remanescente primário de floresta estacional semidecidual em Araguari, Minas Gerais, Brasil. Hoehnea, 36(3), $417-429$.

Viana, M., Tabanez, A. A. J., \& Batista, J. L. F. (1997). Dynamics and restoration of forest fragments in the Brazilian Atlantic moist Forest. In: Laurance, W.F., Bierregard, R.O, ed. Tropical forest remnants: ecology management and conservation of fragmented communities. Chicago: University of Chicago Press, 351-365.

Viapiana, J. (2017). Comparação entre estratos regenerantes de florestas primárias e secundárias: uma avaliação da restauração passiva no Oeste do Paraná. 74f. Dissertação (Mestrado em Tecnologias Ambientais) - Universidade Tecnológica Federal do Paraná.

Vieira, L. S., Santos, W. H. P., Falesi, I. C., \& Oliveira Filho, J. S. (1967). Levantamento de reconhecimento dos solos da região Bragantina, Estado do Pará. Pesquisa Agropecuária Brasileira. 2. 1-63.

Vieira, I. C. G. (1996). Forest succession after shifting cultivation in eastern Amazonia. Scothand. 639Thesis (Ph.D.) - Department of Biological and Molecular Sciences, University of Stirling.

Watrin, O. S., \& Homma, A. K. O. (2007). Evolução do uso da terra do Engenho Murutucu: história, geografia e ecologia. Embrapa Amazônia Oriental. Belém, 48 p.

Watt, A. S. (1947). Pattern and process in the plant community. Journal of Ecology. 35, 1-22.

Whitmore, T. C. (1990). An introduction to the tropical rain forests. Oxford: Clarendon Press. 240. 